\title{
E2F mediates cell cycle-dependent transcriptional repression in vivo by recruitment of an $\mathrm{HDAC} 1 / \mathrm{mSin} 3 \mathrm{~B}$ corepressor complex
}

\author{
Joseph B. Rayman, ${ }^{1}$ Yasuhiko Takahashi, ${ }^{1,4}$ Vahan B. Indjeian, ${ }^{1}$ Jan-Hermen Dannenberg, ${ }^{2}$ \\ Steven Catchpole, ${ }^{3}$ Roger J. Watson, ${ }^{3}$ Hein te Riele, ${ }^{2}$ and Brian David Dynlacht ${ }^{1,5}$ \\ ${ }^{1}$ Department of Molecular and Cellular Biology, Harvard University, Cambridge, Massachusetts 02138, USA; \\ ${ }^{2}$ The Netherlands Cancer Institute, Division of Molecular Biology, 1066 CX Amsterdam, The Netherlands; ${ }^{3}$ Ludwig \\ Institute for Cancer Research, Faculty of Medicine, Imperial College, Norfolk Place, London W2 1PG, UK
}

Despite biochemical and genetic data suggesting that E2F and pRB (pocket protein) families regulate transcription via chromatin-modifying factors, the precise mechanisms underlying gene regulation by these protein families have not yet been defined in a physiological setting. In this study, we have investigated promoter occupancy in wild-type and pocket protein-deficient primary cells. We show that corepressor complexes consisting of histone deacetylase (HDAC1) and $\mathrm{mSin} 3 \mathrm{~B}$ were specifically recruited to endogenous E2F-regulated promoters in quiescent cells. These complexes dissociated from promoters once cells reached late $G_{1}$, coincident with gene activation. Interestingly, recruitment of HDAC1 complexes to promoters depended absolutely on p107 and p130, and required an intact E2F-binding site. In contrast, mSin3B recruitment to certain promoters did not require p107 or p130, suggesting that recruitment of this corepressor can occur via E2F-dependent and -independent mechanisms. Remarkably, loss of pRB had no effect on HDAC1 or mSin3B recruitment. p107/p130 deficiency triggered a dramatic loss of E2F4 nuclear localization as well as transcriptional derepression, which is suggested by nucleosome mapping studies to be the result of localized hyperacetylation of nucleosomes proximal to E2F-binding sites. Taken together, these findings show that p130 escorts E2F4 into the nucleus and, together with corepressor complexes that contain $\mathrm{mSin} 3 \mathrm{~B}$ and/or HDAC1, directly represses transcription from target genes as cells withdraw from the cell cycle.

[Key Words: E2F; Rb; Sin3; HDAC; chromatin; transcriptional control; cell cycle]

Received December 12, 2001; revised version accepted February 27, 2002.

The E2F family of transcription factors is essential for the timely activation of genes involved in DNA replication and cell cycle control, exerting both positive and negative effects on gene expression (for review, see Dyson 1998). There are six known members of the E2F family in mammals, and they form active DNA-binding complexes by heterodimerizing with either DP1 or DP2. E2F activity is controlled in part by interactions with members of the $\mathrm{pRB}$ (pocket protein) family. Individual E2F species exhibit preferential binding to pRB family members (Dyson 1998). For example, E2F1, E2F2, E2F3, and E2F4 interact with pRB, whereas E2F4 and E2F5 interact with p107 and p130. In earlier studies, chromatin immunoprecipitation (ChIP) assays were used to study

\footnotetext{
${ }^{4}$ Present address: Environmental Health Science Laboratory, Sumitomo Chemical Co., Osaka 554-8558, Japan.

${ }^{5}$ Corresponding author.

E-MAIL dynlacht@envoy.mcb.harvard.edu; FAX (617) 496-1391.

Article and publication are at http://www.genesdev.org/cgi/doi/10.1101/ gad.969202.
}

in vivo promoter occupancy by E2F and pocket proteins during the cell cycle (Takahashi et al. 2000; Wells et al. 2000; Ren et al. 2002). This approach showed that E2F4 and p130 form the predominant repressor complex bound to E2F-responsive promoters in quiescent cells. However, E2F4 and p130 disappear from target promoters by late $G_{1}$ following cell cycle re-entry, coincident with histone acetylation and transcriptional activation. Other E2F family members, namely E2F1, E2F2, and E2F3, subsequently replace E2F4, coincident with transcription of target promoters. In addition, E2F target gene expression is reduced in E2F3-deficient mouse embryonic fibroblasts, and these cells exhibit significant proliferative defects (Humbert et al. 2000). These findings are consistent with the notion that E2F4 plays an important role in transcriptional repression, whereas E2F1, E2F2, and E2F3 (Leone et al. 1998; Humbert et al. 2000; Wu et al. 2001) function chiefly in gene activation.

A role for histone deacetylase (HDAC) activity has been proposed to account for one mode of pRB-mediated 
repression (Brehm et al. 1998; Luo et al. 1998; MagnaghiJaulin et al. 1998). The observation that histones $\mathrm{H} 3$ and $\mathrm{H} 4$ are relatively underacetylated in vivo at E2F-regulated promoters during $\mathrm{G}_{0}$ (relative to $S$ phase) supports a model for repression through HDAC (Takahashi et al. 2000; Ferreira et al. 2001). Binding of pocket proteins may also block transactivation by E2F via HDAC-independent (Luo et al. 1998; Ross et al. 1999, 2001) mechanisms. Given that E2F-mediated gene expression in $\mathrm{S}$ phase is associated with increased acetylation of histones $\mathrm{H} 3$ and $\mathrm{H} 4$ (Takahashi et al. 2000), it is possible that recruitment of the activator class of E2Fs (E2F1, E2F2, and E2F3) displaces an HDAC activity recruited earlier in the cell cycle. A second, nonmutually exclusive possibility is that activator E2Fs recruit histone acetyltransferase (HAT) activity to the promoter, facilitating changes in chromatin structure that enable gene expression. Consistent with this hypothesis, E2F is able to interact with the CBP HAT in vitro and in transiently transfected cells (Trouche et al. 1996). In addition, previous studies have shown that $\mathrm{pRB}$ family members can associate with chromatin remodeling factors such as SWI/SNF (Dunaief et al. 1994; Strober et al. 1996).

Recently, it has been suggested that different classes of chromatin-modifying factors may be recruited to promoters as multi-enzyme corepressor complexes. For example, mSin 3 forms a corepressor complex by acting as a scaffold for the assembly of specific HDAC and SWI/SNF components (for review, see Alland et al. 1997; Hassig et al. 1997; Laherty et al. 1997; Nagy et al. 1997; Knoepfler and Eisenmann 1999; Sif et al. 2001). mSin3 can be recruited to promoters as an mSin3/HDAC complex by several different DNA-binding transcription factors, including Max, Ume6, and nuclear hormone receptors (Ayer et al. 1995; Schreiber-Agus et al. 1995; Kadosh and Struhl 1997; Washburn and Esposito 2001), suggesting a way in which various chromatin-modifying activities can be specifically targeted to promoters. Furthermore, both the variable subunit composition and stoichiometry of $\mathrm{mSin} 3$ complexes are consistent with multiple functional roles in a variety of transcriptional contexts (Knoepfler and Eisenmann 1999).

Despite significant advances in our understanding of the relationship between chromatin structure, chromatin-modifying factors, and transcriptional regulation by $\mathrm{E} 2 \mathrm{~F} / \mathrm{pRB}$ proteins, a complete characterization of the identity and temporal specificity of physiologically relevant factors that are directly recruited to E2F-regulated promoters has not been achieved. In this study, we have investigated the in vivo association of corepressor complexes with E2F-regulated genes using cross-linking and ChIP. We show that HDAC1 and $\mathrm{mSin} 3 \mathrm{~B}$ associate with endogenous promoters of living, primary cells during quiescence, but these complexes dramatically dissociate from promoters between mid- $G_{1}$ and $S$ phase, coincident with gene activation. Thus, the pattern of promoter occupancy by $\mathrm{mSin} 3 \mathrm{~B} / \mathrm{HDAC} 1$ suggests an exclusive role for these factors in transcriptional repression during cell cycle exit. ChIP experiments using pocket protein-deficient cells indicate that either p107 or p130, but not pRB, is strictly required for promoter association of HDAC1. In contrast, on some promoters, mSin3B occupancy did not absolutely require any of these pocket proteins, suggesting the potential for differential gene regulation. Interestingly, the absence of both p107 and p130 also resulted in the failure of E2F4 nuclear localization during quiescence, implying that these pocket proteins are required for the proper localization of this repressor. Collectively, these results provide direct, physiological evidence for a link between E2F, specific members of the pRB family, chromatin-modifying factors, and regulation of gene expression during the mammalian cell cycle.

\section{Results}

Recruitment of E2F and $p R B$ family members in mouse cells

We have previously studied promoter occupancy in living human cells using an in vivo cross-linking and ChIP approach. These experiments revealed dynamic changes in promoter occupancy by E2F and pRB family members during the cell cycle (Takahashi et al. 2000). We sought to extend these studies to mouse cells to allow for the use of cells singly and combinatorially deficient for E2F and pocket proteins. We first established conditions for synchronizing $3 \mathrm{~T} 3$ cells by serum withdrawal and restimulation. FACS analysis allowed us to determine the degree of enrichment of cells at each stage of the cell cycle (Fig. 1A). After serum withdrawal, typically $80 \%-$ $90 \%$ of cells were arrested as a $\mathrm{G}_{0} / \mathrm{G}_{1}$ cell population, and $18-20 \mathrm{~h}$ after serum addition, $70 \%-80 \%$ of cells have entered S phase. Thus, it is possible to achieve the high degree of synchrony required for this analysis.

To determine promoter occupancy by E2F and $\mathrm{pRB}$ family members, ChIP was performed using $3 \mathrm{~T} 3$ cells at various cell cycle time points, and PCR was performed using primers flanking potential E2F-binding site(s) (Fig. 1B). ChIP analysis revealed robust binding by E2F4 and p130 to all E2F-responsive promoters in quiescent cells, but recruitment of both proteins was dramatically reduced by $\mathrm{S}$ phase (Fig. 1C). As expected, the actin gene, which is not thought to be an E2F target, was not significantly enriched and serves as a negative control in all subsequent ChIP experiments. As an additional control for specificity, we showed that an irrelevant antibody was unable to enrich each of the various E2F target genes in these experiments (mock lanes). Thus, with respect to E2F4 and p130 recruitment during the cell cycle, murine and human cells are qualitatively similar.

We did note one interesting distinction between human and mouse cells, namely, that p107 associated with promoters in quiescent 3T3 cells but not in human cells (Fig. 1C). We have ruled out cross-reactivity of the antip107 antibody by performing ChIP analysis using 3T3 cells and MEFs that lack p107 (data not shown). Therefore, it is possible that the presence of p107 on E2F-responsive promoters in mouse cells reflects a bona fide difference between the two species. Because promoter association by p107 is more pronounced in $3 \mathrm{~T} 3$ cells 
A

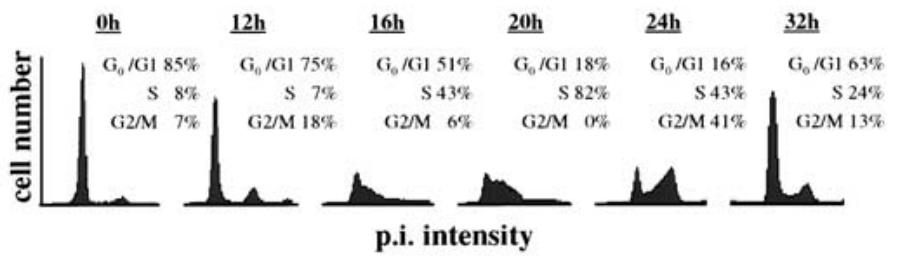

B

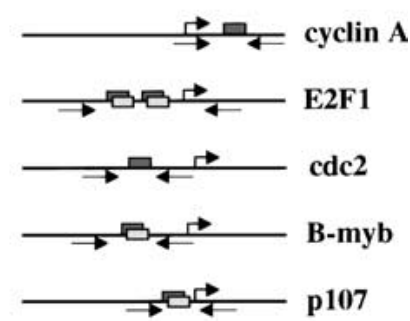

C

$\underline{\mathrm{E} 2 \mathrm{~F} 1}$

$\underline{\operatorname{cdc} 2}$

$\underline{\operatorname{actin}}$
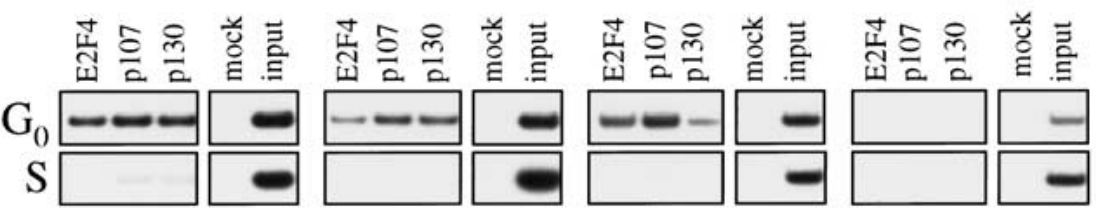

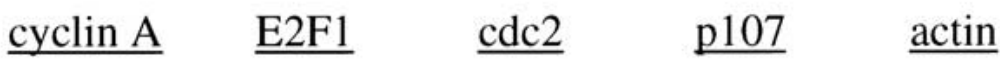

D

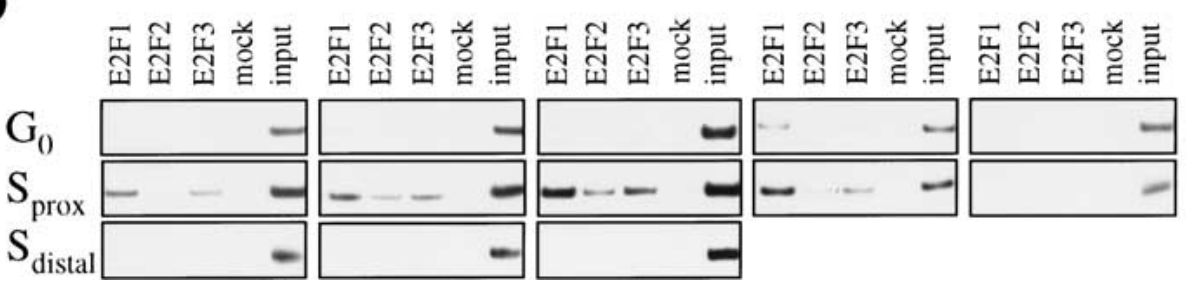

Figure 1. In vivo promoter occupancy by E2F and pRB family proteins in mouse cells. $(A)$ Wild-type $3 \mathrm{~T} 3$ cells were rendered quiescent by serum deprivation. Cells were stimulated to re-enter the cell cycle by serum addition, harvested at the indicated time points, and examined by FACS analysis. DNA content was determined by propidium iodide (p.i.) staining and is plotted versus cell number. $(B)$ Schematic of promoters analyzed in this study. Boxes represent previously identified E2F-binding sites. For each schematic, lower arrows indicate positions of PCR primers used to detect promoter fragments, whereas upper arrows represent the major transcription start site as determined in earlier studies. $(C, D)$ ChIP analysis of synchronized wild-type 3T3 cells. Promoters are underlined. Input represents $0.5 \%$ of total amount of chromatin added to each immunoprecipitation reaction. The mock lane corresponds to a negative control immunoprecipitation using an irrelevant antibody. Proximal promoter sequences $\left(G_{0}\right.$ and $\left.S_{\text {prox }}\right)$ were amplified by PCR using primers specified in the schematic, whereas distal sequences $\left(\mathrm{S}_{\text {distal }}\right)$ were detected with primers corresponding to regions $1-2 \mathrm{~kb}$ upstream of the E2F-binding site(s). PCR products were detected by autoradiography. PCR products shown in the input, mock, and specific immunoprecipitation lanes were obtained in the same experiment.

than in primary MEFs, there may also be cell type-specific explanations for this phenomenon (cf. Fig. 1C and Fig. 3, below). The similarity of binding profiles suggests that both p107 and p130 are capable of collectively contributing to transcriptional repression during quiescence. In contrast to p107 and p130, we have not detected pRB binding to any of the promoters in this study, an observation that extends to a number of additional mouse and human cell lines that we have tested (data not shown). To rule out the possibility that $\mathrm{pRB}$ is nonfunctional in our 3T3 cell line, ChIPs were also performed in primary mouse embryonic fibroblasts (MEFs), and similar negative results were obtained (Fig. 2D). Our results are largely consistent with those of a previous study in which 3T3 cells were analyzed (Wells et al. 2000). One notable difference, however, was that these authors detected occupancy of the $c d c 2$ promoter by all three pRB family members in S phase, whereas we did not detect promoter occupancy by pocket proteins at this stage of the cell cycle.

In striking contrast to E2F4, promoter occupancy by
E2F1 and E2F3 peaked in S phase, coincident with elevated levels of transcription (Fig. 1D, $S_{\text {proxi }}$ data not shown). Because ChIP data must be interpreted in light of the size of chromatin fragments produced by sonication, we performed additional controls to ensure that the ChIP signals were produced by specific enrichment of proximal promoter DNA rather than distal sequences. As shown in Figure 1D $\left(\mathrm{S}_{\text {distal }}\right)$, PCR amplification of promoter regions $1-2 \mathrm{~kb}$ upstream from the E2Fbinding site(s) revealed no enrichment of E2F1-E2F3. Binding of promoter-proximal factors was also shown for wild-type quiescent MEFs (Fig. 2D), confirming that the ChIP data reflect occupancy of the designated promoters by the factors under study. Therefore, we conclude that in mouse cells, the pattern of promoter occupancy by $\mathrm{E} 2 \mathrm{~F}$ and pocket proteins is comparable with that of human cells. Taken together, these findings reinforce the observation that p107 and p130 play a significant role in the regulation of selected E2F-responsive promoters as cells withdraw from the cell cycle and enter a quiescent state. 
Rayman et al.

A

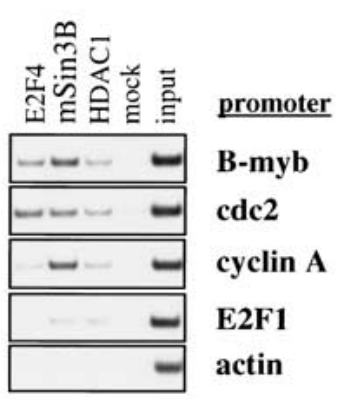

$\mathbf{C}$

time (hr) $\quad 0 \quad 6 \quad 6 \quad 12 \quad 18 \quad 20$

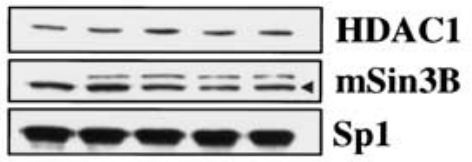

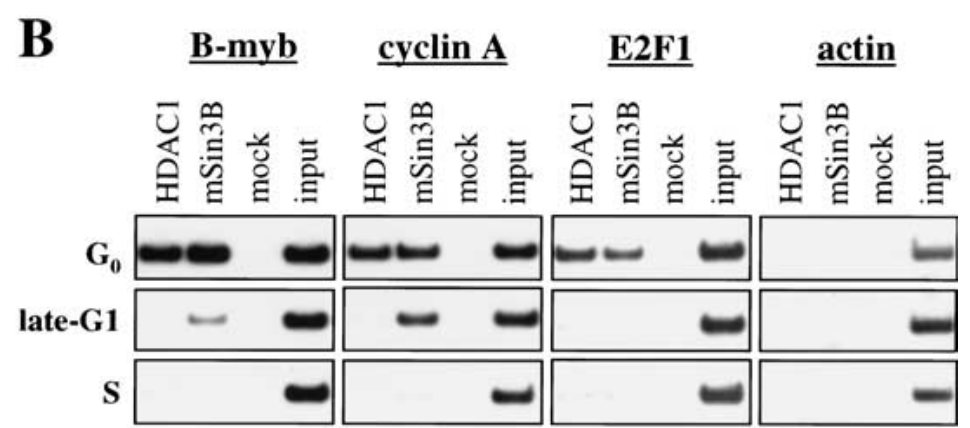

D

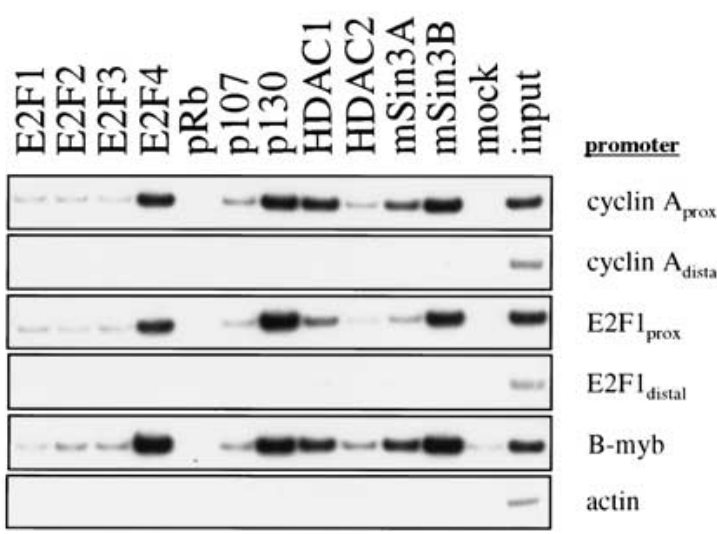

Figure 2. Detection of corepressors associated with E2F-responsive promoters in growing cells and cells in different cell cycle stages. (A) Analysis of in vivo promoter occupancy in asynchronous cultures of wild-type 3T3 cells. Chromatin immunoprecipitations were performed as described in Figure 1 using the indicated antibodies. (B) 3T3 cells were brought to quiescence by serum deprivation and subsequently stimulated to re-enter the cell cycle by the addition of serum. Chromatin was prepared at $0 \mathrm{~h}\left(\mathrm{G}_{0}\right), 12 \mathrm{~h}$ (late- $\mathrm{G}_{1}$ phase), and $18 \mathrm{~h}$ (S phase) following cell cycle re-entry. Chromatin immunoprecipitations were performed as described in Figure 1. (C) Presence of $\mathrm{mSin} 3 \mathrm{~B}$ and HDAC1 in nuclear extracts. Wild-type 3T3 cells were harvested at the indicated time points upon release from quiescence. Nuclear extracts were prepared and analyzed by Western blotting using the specified antibodies. The mSin $3 \mathrm{~B}$ band is indicated by the small arrow. The top band observed in the $\mathrm{mSin} 3 \mathrm{~B}$ blot comigrates with a band detected by anti-mSin $3 \mathrm{~A}$ antibody (data not shown). The same blot was stripped and reprobed sequentially. Sp1 serves as a nuclear marker. $(D)$ Promoter occupancy of quiescent MEFs. Wild-type primary MEFs were rendered quiescent by serum withdrawal, and promoter occupancy of E2F-responsive genes was determined by ChIP. Enrichment of proximal and distal promoter sequences was performed as described in Figure 1.

\section{Recruitment of HDAC and mSin3 to promoters} in asynchronous cells

Because enhancement of histone acetylation coincided with transcription of E2F-responsive genes in our previous study with human cells, we next asked whether it is possible to detect recruitment of HDACs. Initially, we performed experiments using cycling $3 \mathrm{~T} 3$ cells. As shown in Figure 2A, HDAC1 bound each of the E2Fresponsive genes we examined, including $B-m y b, c d c 2$, cyclin $A$, and E2F1. We have examined promoter occupancy by additional HDAC family members and did not observe significant binding (data not shown). We also detected robust binding by $\mathrm{mSin} 3 \mathrm{~B}$, a corepressor protein known to associate with chromatin-modifying factors, including HDAC1. These results imply that regulation of E2F-responsive genes in cycling cells involves recruitment of a chromatin-modifying activity containing $\mathrm{mSin} 3 \mathrm{~B}$ and HDAC1, prompting us to investigate whether the recruitment of these factors is cell cycleand E2F-dependent.
Promoter occupancy by mSin3B/HDAC1 during the cell cycle

We reasoned that $\mathrm{mSin} 3 \mathrm{~B}$ and $\mathrm{HDAC} 1$ might be important for transcriptional repression of E2F-regulated genes during quiescence and early $G_{1}$ phase and tested whether promoter occupancy by these factors might be cell cycledependent. We synchronized wild-type $3 \mathrm{~T} 3$ cells by serum deprivation and restimulation and analyzed the binding of this corepressor as a function of cell cycle progression (Fig. 2B). Remarkably, the data show that HDAC1 is recruited to promoters during quiescence, but it dramatically disappears from promoters by $12 \mathrm{~h}$ poststimulation, coinciding with a point in mid-to-late $G_{1}$, when transcription of these genes is activated (Fig. 2B; data not shown). The mSin3B signal is likewise enriched in quiescent cells relative to continuously cycling cells. Interestingly, loss of HDAC1 binding preceded the disappearance of $\mathrm{mSin} 3 \mathrm{~B}$ from the $B-m y b$ and cyclin $A$ promoters, although both proteins appear to dissociate from the E2F1 promoter simultaneously. We have also de- 
tected promoter occupancy by a second HDAC family member, HDAC2 (Fig. 2D; data not shown). Promoter enrichment by anti-HDAC2 antibodies is relatively reduced compared with that of HDAC1, an observation that may be explained by differences in factor association, antibody affinity, and/or epitope accessibility. Both of these HDACs exhibit a high degree of similarity in their catalytic domains, but their functional differences have not been fully elucidated (for review, see Khochbin et al. 2001). These ChIP data are consistent with the observation that HDAC1 and HDAC2, which both belong the class I HDAC subfamily, are found together in multiprotein complexes in vivo (Zhang et al. 1997; Knoepfler and Eisenmann 1999; Sif et al. 2001). In contrast, we have not detected recruitment of HDAC5, a class II HDAC, suggesting specificity at the level of corepressor recruitment (data not shown). We have also attempted to detect recruitment of $\mathrm{mSin} 3 \mathrm{~A}$, a protein highly related to $\mathrm{mSin} 3 \mathrm{~B}$ that is found in complexes with HDAC1 and HDAC2. mSin $3 \mathrm{~A}$ is detectable on promoters in quiescent MEFs (Fig. 2D). However, we did not investigate whether the reduced intensity of the mSin3A signal relative to that of $\mathrm{mSin} 3 \mathrm{~B}$ is a reflection of the level of promoter association of $\mathrm{mSin} 3 \mathrm{~A}$, differences in antibody performance, and/or antibody cross-reactivity against mSin3B (see Fig. 3B). We decided to focus our attention on HDAC1 and $\mathrm{mSin} 3 \mathrm{~B}$, because the corresponding antibodies consistently and robustly enriched E2F-responsive promoters in our ChIP assays.

\section{Abundance and subcellular localization of $m \operatorname{Sin} 3 B$ and HDAC1 during the cell cycle}

We investigated whether a corresponding decrease in the abundance or change in subcellular localization of this protein could account for the disappearance of HDAC1 from selected promoters during cell cycle progression. Interestingly, although HDAC1 and $\mathrm{mSin} 3 \mathrm{~B}$ are not recruited to any of the promoters thus far examined during $S$ phase, both proteins are equally abundant in nuclear extracts of quiescent and S-phase cells (Fig. 2C). Hence, $\mathrm{HDAC} 1$ is selectively recruited to E2F-responsive genes during $G_{0}$, although it may be free to participate in the regulation of a distinct set of genes later in the cell cycle. Taken together, these findings strongly suggest that
HDAC1 and mSin3B are physiological effectors of transcriptional repression of E2F-responsive genes during quiescence. The recruitment of both proteins to promoters in cycling cells also suggests that their role in gene regulation may not be restricted to quiescent cells.

\section{Dependency of mSin3B/HDAC1 binding on pocket proteins}

Having found that the association of $\mathrm{mSin} 3 \mathrm{~B}$ and HDAC1 with selected promoters occurs as a function of the cell cycle, we next sought to determine whether recruitment of these corepressors is dependent on the E2F and $\mathrm{pRB}$ families. The physiological association between E2F and pRB family members is well established, and biochemical studies have shown that $\mathrm{pRB}$ is able to interact with mSin 3 and HDAC (Lai et al. 1999, 2001; Ferreira et al. 1998). However, these and other studies focused largely on pRB and did not extensively address the potential contribution of mSin3/HDAC interactions with $\mathrm{p} 130$, which we find is the predominant $\mathrm{pRB}$ family member localized to E2F-responsive promoters during quiescence. Our experimental approach was to perform ChIPs in cells that are singly or combinatorially deficient for pRB family members to explore the possible involvement of p130 and p107 in corepressor recruitment. We reasoned that any observed reduction in promoter occupancy by HDAC $1 / \mathrm{mSin} 3 \mathrm{~B}$ in mutant cells might reflect a requirement for pocket proteins and, by extension, E2F.

As indicated earlier, our results suggested that p107 and p130 associate with promoters in wild-type $3 T 3$ cells during quiescence. Given the overlapping functions of p107 and p130 in vivo (Cobrinik et al. 1996; Hurford et al. 1997), we investigated HDAC1 and $\mathrm{mSin} 3 \mathrm{~B}$ recruitment in quiescent cells deficient for both pocket proteins. Initially, we performed ChIP experiments with $p 107^{-/-} ; p 130^{-/-}$3T3 cells that we derived from doubly deficient MEFs (Cobrinik et al. 1996; Hurford et al. 1997). However, during the course of these experiments, we noted a strong and reproducible enrichment of E2F-regulated genes by use of two different antip130 antibodies, despite the fact that the targeted p130 alleles contained a stop codon in the second exon (data not shown). Moreover, ChIPs performed by use of the

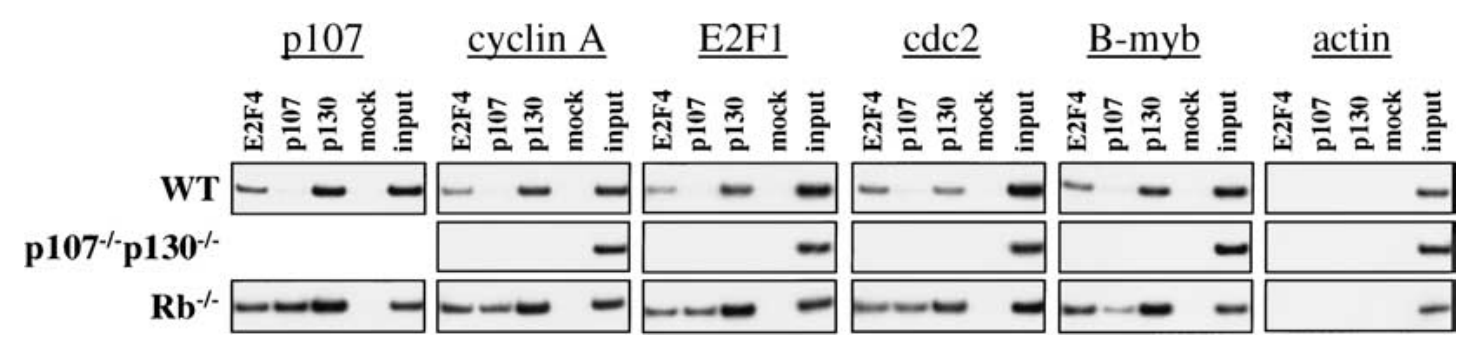

Figure 3. Dependency of E2F4 recruitment on pRB family members in vivo. Wild-type, $p 107^{-/-}$; $p 130^{-/-}$, and $R B^{-/-}$primary MEFs were arrested by serum deprivation and analyzed by ChIP as in Figure 1 using the indicated antibodies. Interestingly, p107 binding is increased at several promoters in $\mathrm{RB}^{-/-} \mathrm{MEFs}$, but not in the wild-type controls. It is possible that this phenomenon is related to the observed up-regulation of p107 protein levels in $\mathrm{RB}^{-/-}$cells (Hurford et al. 1997). 
original MEFs yielded similar results (data not shown). These and other biochemical studies suggested that the $p 107^{-/-}$; $p 130^{-/-}$MEFs were not deficient for p130 and may contain a novel form of this protein $(\mathrm{H}$. Cam, J. Rayman, F. Rossi, D. Cobrinik, and B.D. Dynlacht, unpubl.). To circumvent this potential complication, we analyzed an independently derived preparation of p107 ${ }^{-/-}$; $p 130^{-/-}$primary MEFs (Dannenberg et al. 2000). As expected for truly null cells, recruitment of p107 and p130 to multiple E2F-responsive genes was completely abolished, although we observed significant promoter occupancy by p130 (and to a lesser extent p107) in wildtype isogenic MEFs (Fig. 3, top). Hence, this preparation of $p 107^{-/-} ; p 130^{-/-}$MEFs was used in all subsequent experiments.

Next, we performed ChIPs to detect HDAC1 and $\mathrm{mSin} 3 \mathrm{~B}$. Both HDAC1 and $\mathrm{mSin} 3 \mathrm{~B}$ were bound to all E2F-responsive genes tested in wild-type, quiescent MEFs (Fig. 4, top). In contrast to isogenic wild-type controls, promoter occupancy by HDAC1 was dramatically reduced to near-background levels in the $p 107^{-/-} ; p 130^{-/-}$ MEFs. We estimate that enrichment by HDAC1 antibodies is reduced by 7 - to 10 -fold in the mutant cells, and in many experiments HDAC1 was undetectable. Because p130 is the predominant pocket protein bound in quiescent MEFs (Fig. 3), we interpret these results to mean that the recruitment of HDAC1 is largely dependent on E2F4/p130 in wild-type primary cells.

Remarkably, mSin3B recruitment varied considerably between different promoters in the double knockout cells (Fig. 4A). At one end of the spectrum, the cyclin $A$, $c d c 2$, and E2F1 promoters retained significant levels of $\mathrm{mSin} 3 \mathrm{~B}$ in the absence of $\mathrm{p} 107 / \mathrm{p} 130$, whereas loss of these pocket proteins nearly abolished binding to the $B-m y b$ promoter. Thus, $\mathrm{p} 107$ and $\mathrm{p} 130$ are required for recruitment of $\mathrm{mSin} 3 \mathrm{~B}$ to some, but not all, E2F-regulated promoters. These data suggest that E2F4 and p130 mediate transcriptional repression of the $B-m y b$ promoter by recruiting a corepressor complex that contains both HDAC1 and $\mathrm{mSin} 3 \mathrm{~B}$ (a notion substantiated further in our $B-m y b$ stable cell lines below). It appears likely in other cases, however, that DNA-binding proteins apart from $\mathrm{E} 2 \mathrm{~F}$ can recruit $\mathrm{mSin} 3 \mathrm{~B}$, but not $\mathrm{HDAC1}$, in an E2F-independent manner and that on these promoters, recruitment of $\mathrm{mSin} 3 \mathrm{~B}$ and $\mathrm{HDAC} 1$ can occur independently.

Similar ChIP experiments were also performed with $p 107^{-/-}$and $p 130^{-/-}$single knockout MEFs to determine whether the absence of either pocket protein would have an impact on corepressor recruitment. ChIP data indicate that recruitment of $\mathrm{mSin} 3 \mathrm{~B}$ and HDAC1 was minimally affected by loss of either protein individually (Fig. 4B). In these experiments, the absence of one pocket protein led to compensation by the remaining one, as we detected robust promoter association of p107 in the absence of p130 (data not shown). These data are consistent with earlier studies suggesting that p107 and p130 share a substantial degree of functional redundancy (Hurford et al. 1997). We interpret these findings to suggest that both p107 and p130 are capable of mediating the recruitment

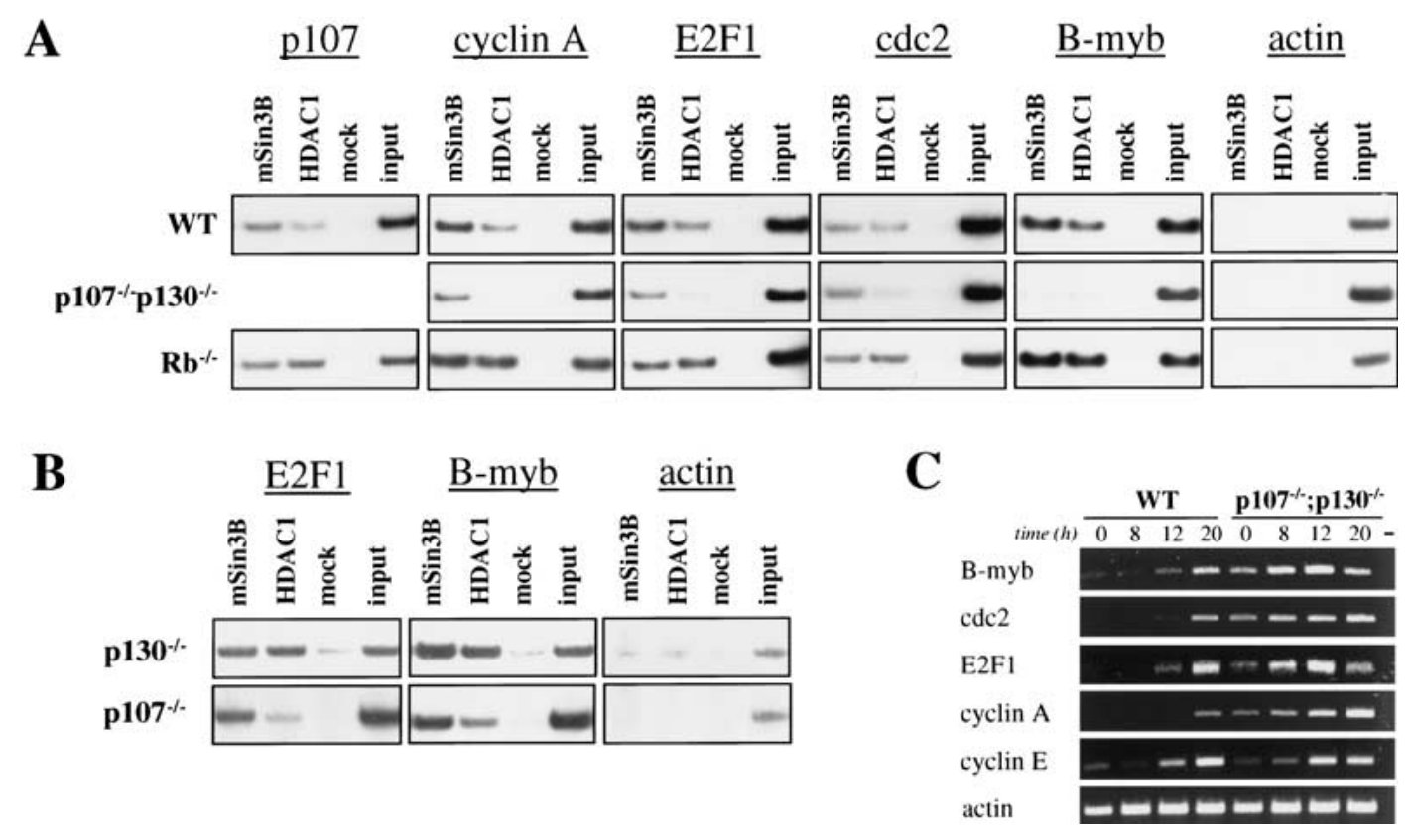

Figure 4. (A) Dependency of mSin3B/HDAC1 corepressor recruitment on $\mathrm{pRB}$ family members in vivo. Wild-type, $p 107^{-/-} ; \mathrm{p} 130^{-/-}$, and $R B^{-/-}$primary MEFs were arrested by serum deprivation and analyzed by ChIP as in Figure 1 using the indicated antibodies. $|B|$ ChIP analysis of corepressor recruitment in $107^{-/-}$and $p 130^{-/-}$quiescent primary MEFs. (C) Analysis of gene expression in wild-type versus $p 107^{-/-} ; p 130^{-/-}$primary MEFs. Cells of low passage number were synchronized as in Figure 1. Total RNA was prepared at each of the indicated time points and subjected to RT-PCR analysis by use of cDNA-specific primers. Actin gene expression is used as a loading control. (-) Lane corresponding to a no-template control. 
of HDAC-containing corepressor complexes to E2F-responsive promoters in vivo. However, as mentioned above, the ChIP data from wild-type MEFs suggest that p130 is the predominant pRB family member normally responsible for corepressor recruitment during quiescence.

Transcriptional derepression in $\mathrm{p} 107^{-/-}$; $\mathrm{p} 130^{-/-}$MEFS

Promoter recruitment of HDAC1 and, to a variable de-

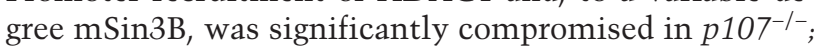
p130-/- cells. We therefore assessed the impact of $\mathrm{p} 107 /$ p130 loss on transcription of a subset of E2F-regulated genes. Wild-type and $p 107^{-/-} ; p 130^{-/-}$MEFs were synchronized by serum starvation and restimulation, and transcription was analyzed by use of a coupled RT-PCR protocol. Analysis of wild-type cells revealed that the $B$ - $m y b, E 2 F-1$, and cyclin $E$ promoters were induced in late $\mathrm{G}_{1}$ phase, and $c d c 2$ and cyclin $A$ were induced in $S$ phase following cell cycle re-entry, as expected (Fig. 4C). Transcription of the $B-m y b$, cyclin $A, c d c 2$, and E2F1 genes was significantly derepressed in quiescent $p 107^{-/-}$; p130 ${ }^{-/-}$MEFs in comparison with wild-type controls. In contrast, the cyclin E gene was not derepressed in these p107 ${ }^{-/-}$; $p 130^{-/-}$MEFs. These data are consistent with earlier studies using independently derived double knockout MEFs (Hurford et al. 1997). Thus, both $p 107^{-1-}$; $p 130^{-/-}$MEF preparations behave similarly in these experiments.

Promoter occupancy by $\mathrm{mSin} 3 B$ and HDAC1 does not require $p R B$

It is clear that in some settings, $\mathrm{mSin} 3 \mathrm{~B}$ and HDAC1 recruitment required the integrity of p107 and p130. Nevertheless, it was necessary to address the impact of $\mathrm{pRB}$ on the recruitment of these corepressors to promoter regions, because ectopic expression studies in cancer cells have suggested that a pRB-HDAC complex plays an important role in transcriptional repression (Zhang et al. 2000; Dahiya et al. 2001). If this were the case, then loss of pRB would be expected to have a measurable effect on promoter occupancy by HDAC1 and perhaps $\mathrm{mSin} 3 \mathrm{~B}$. Interestingly, ChIP analysis showed that the absence of $\mathrm{pRB}$ did not compromise recruitment of either of these factors in primary MEFs; in fact, promoter occupancy by these proteins increased modestly in the absence of pRB (Fig. 4A). Whereas studies on interactions between HDACs and pRB family members have largely focused on the involvement of $p R B$, these data underscore a strict requirement for p107/p130, but not $\mathrm{pRB}$, in the recruitment of this chromatin-modifying activity in quiescent primary cells under physiological conditions

p107 and p130 are required for the nuclear localization of E2F4

Our ChIP experiments suggested that p107 and p130, but not $\mathrm{pRB}$, were required to recruit the HDAC corepressor
(Fig. 4A). Remarkably, use of pocket protein-deficient MEFs also led to another surprising finding. We found that in the absence of p107 and p130, E2F4 was no longer recruited to any E2F-responsive promoter during quiescence (Fig. 3). In contrast, pRB deficiency had no obvious effect on E2F4 recruitment. We hypothesized that p107/ p130 might have a role in the stabilization and/or subcellular localization of E2F4. To address these possibilities, nuclear and cytoplasmic extracts were prepared from quiescent wild-type and $p 107^{-/-} ;$p130 $130^{-/-}$MEFs, and we verified the success of this protocol by Western blot detection of two well-established markers (Fig. 5). In quiescent wild-type cells, E2F4 is predominantly located in the nucleus, in agreement with earlier reports (Lindeman et al. 1997; Muller et al. 1997; Verona et al. 1997; Gaubatz et al. 2001). In striking contrast, most of the E2F4 is found in the cytoplasm of p107/p130-deficient MEFs, suggesting that p107 or p130 are needed to facilitate nuclear localization of E2F4. These data are supported by immunofluorescence experiments in which we compared wild-type and doubly deficient MEFs and 3T3 cells (data not shown). Stability of E2F4 was not affected by p107/p130 loss, because the overall levels of E2F4 protein were similar in both cell types. Apparently, either p107 or p130 is sufficient to promote E2F4 nuclear localization, because promoter association by E2F4 was not compromised in $p 107^{-/-}$or $p 130^{-/-}$cells (data not shown). Low levels of E2F4 remain in nuclear extracts of mutant cells, most likely reflecting the significantly less-abundant E2F4-pRB complex that is nevertheless unable to bind to the promoters in our study.

\section{mSin3B/HDAC1 promoter association requires an intact E2F-binding site}

Although promoter occupancy of the $B-m y b$ promoter by $\mathrm{E} 2 \mathrm{~F} / \mathrm{pRB}$ proteins during quiescence was similar to that of other promoters in this study (Fig. 6A), the extent of loss of $\mathrm{mSin} 3 / \mathrm{HDAC} 1$ recruitment for the $B$-myb promoter in $p 107^{-/-} ; p 130^{-/-}$MEFs was the most severe (Fig. 4A). These data suggested that transcriptional repression of the $B-m y b$ promoter during quiescence may be mediated by a complex that contains E2F4, p130, HDAC1,

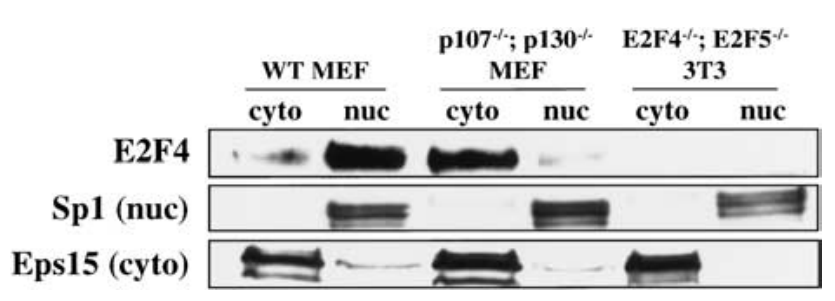

Figure 5. Subcellular localization of E2F4 in quiescent cells depends on pRB family members. Nuclear and cytoplasmic fractions of quiescent cells were prepared and analyzed by immunoblotting using anti-E2F4 antibody. To verify the purity of each fraction, the same filter was stripped and subsequently reprobed with anti-Sp1 and anti-Eps15 antibodies, which serve as nuclear and cytoplasmic markers, respectively. 


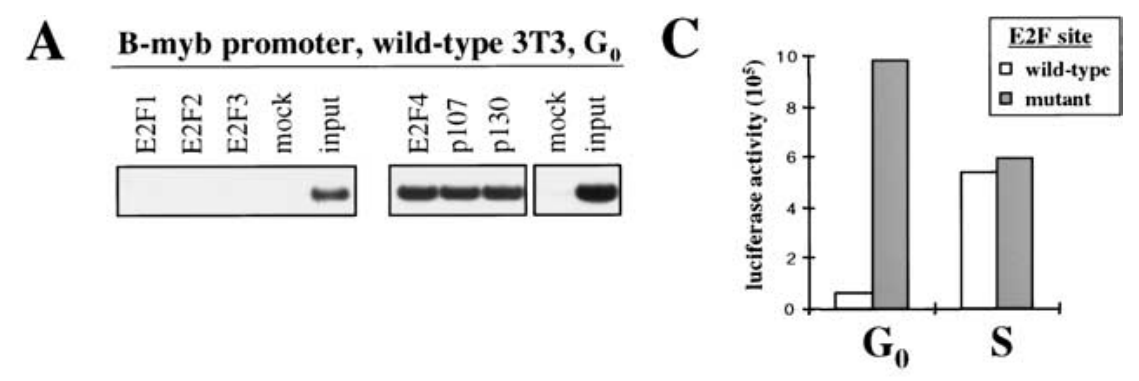

Figure 6. A functional E2F-binding site is required for recruitment of E2F and corepressors. (A) $B$-myb promoter occupancy in wildtype NIH-3T3 during quiescence. ChIPs using the indicated antibodies were performed as before. (B) NIH-3T3 cell lines were stably transfected with $B-m y b$ reporter constructs, in which promoter DNA (positions -536 to -88 relative to the translation start site) is linked to a luciferase gene. Stable cell lines were generated with wild-type and E2F-site mutant $B$-myb transgenes. Cells were brought to quiescence by serum deprivation and analyzed by ChIP. Small arrows represent PCR primers used to distinguish endogenous $(1$ and 2$)$ and transgenic ( 1 and 3$)$ promoters. $(C)$ Luciferase activity was measured by luminometry using extracts from synchronized cells harvested at $G_{0}$ and $S$ phase, and normalized on the basis of cell number.

\section{B}

WT NIH 3T3 cell line
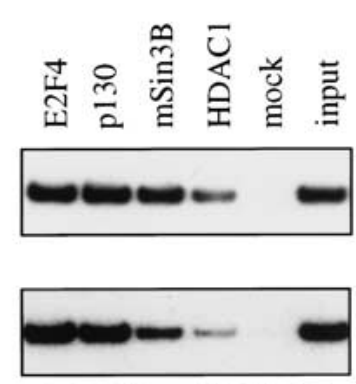

CTTGGCGGGAGA
E2F-site mutant NIH 3 T3 cell line

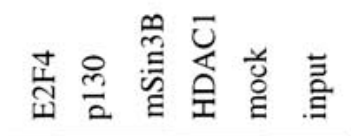

endogenous

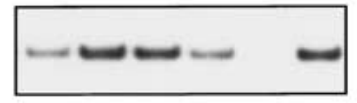

transgene

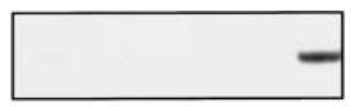

CTTGTATGGAGA

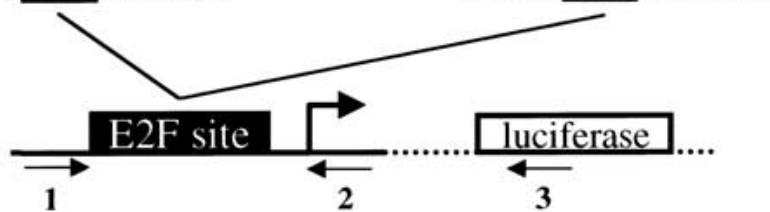

and $\mathrm{mSin} 3 \mathrm{~B}$. For other promoters, E2F could potentially mediate repression by recruiting p130 and HDAC1, but not $\mathrm{mSin} 3 \mathrm{~B}$. Nevertheless, the results did not exclude the possibility that recruitment of $\mathrm{mSin} 3 / \mathrm{HDAC}$ corepressor complexes might be E2F-independent, because p130 and mSin3B/HDAC1 have been shown to interact with other sequence-specific transcription factors. To test this possibility, we engineered stable NIH-3T3 cell lines carrying a $B-m y b$ promoter linked to a luciferase reporter (Fig. 6B). Importantly, this promoter fragment is sufficient to confer on the reporter both E2F responsiveness and the cell cycle periodicity (i.e., transcriptional repression in $\mathrm{G}_{0}$ and derepression in $\mathrm{S}$ phase) of the endogenous $B$-myb gene (Lam and Watson 1993; Fig. 6C). We engineered a second cell line containing the same reporter, in which we have mutated the E2F-binding site with a 3-bp substitution (Fig. 6B, bottom right). This mutation eliminates binding by E2F in vitro (data not shown). To reduce the likelihood of positional effects, the reporter was flanked with insulator elements. We performed luciferase assays on both cell lines and confirmed that the integrated reporter recapitulates transcriptional regulation of the endogenous promoter, because an intact E2F site was required to confer transcriptional repression in quiescent cells (Fig. 6C).

Next, ChIP assays were performed to assess the occupancy of both wild-type and mutant promoters in quiescent cells. Robust binding of E2F4, p130, mSin3B, and HDACl to the endogenous $B$-myb promoter was observed in both cell lines (Fig. 6B), in agreement with our

experiments using other mouse cell lines (Figs. 2B, 3, 4, and 6A). Furthermore, each of these proteins was recruited to the wild-type transgenic promoter, confirming the utility of this assay. In marked contrast, binding of this E2F4-repressor complex is virtually undetectable on the E2F-site mutant transgene. We conclude that E2F4 is required for localization of the $\mathrm{mSin} 3 \mathrm{~B} / \mathrm{HDAC} 1$ corepressor complex to the $B-m y b$ promoter in quiescent cells. Moreover, these results are consistent with our MEF experiments in which we showed a requirement for p130 and E2F4 in the recruitment of HDAC1 to the $B$ $m y b$ promoter (Figs. 3 and 4 ). In addition, $m S i n 3 B$ recruitment also strictly required E2F binding, again consistent with our MEF experiments. This result suggests that $\mathrm{mSin} 3 \mathrm{~B}$ is recruited concomitantly with HDAC1, unlike other promoters (Fig. 4). However, location of a factor at a promoter does not necessarily mean that it serves a regulatory role. Importantly, we could show that the mutant promoter is significantly derepressed in quiescent cells relative to the wild-type construct (Fig. 6C), strongly suggesting that transcriptional repression of $B$ $m y b$ (and most likely other E2F-responsive genes) is mediated in vivo by a single complex that contains E2F4, p130, mSin3B, and HDAC1.

Local histone acetylation is increased in $\mathrm{p} 107^{-/-}$; $\mathrm{p} 130^{-/-}$MEFs

We reasoned that repression of E2F-regulated promoters could occur through the recruitment of $\mathrm{mSin} 3 / \mathrm{HDAC}$ in 
$\mathrm{G}_{0} /$ early $\mathrm{G}_{1}$, resulting in histone deacetylation, whereas subsequent loss of this corepressor in late- $G_{1}$ might be expected to shift the balance of nucleosome acetylation to a hyperacetylated state, leading to gene activation. Furthermore, we hypothesized that loss of pocket proteins required for HDAC recruitment should lead to hyperacetylation of nucleosomal histones. To test these hypotheses, it was first necessary to define the location of promoter nucleosomes, because acetylation is often thought to occur in a localized manner (Parekh and Maniatis 1999). We analyzed the mouse E2F1 promoter because the occupancy and activity of this promoter has been well characterized at different stages of the cell cycle using ChIP and expression analysis, and its transcription start site has been accurately mapped (Hsiao et al. 1994; Takahashi et al. 2000).

We partially digested chromatin from cross-linked, quiescent wild-type 3T3 cells with micrococcal nuclease (MNase), and after reversal of cross-links, used the DNA as a template in primer extension and ligation-mediated
PCR (LM-PCR) reactions (see Materials and Methods). We identified three promoter-proximal nucleosomes flanking the E2F sites (Fig. 7A, labeled Nuc- $\alpha$, a, and b). Interestingly, the E2F sites are partially overlapping with Nuc-a, whereas the transcription start site is located within the nucleosome region. We confirmed the assignment of these nucleosome locations by use of a second method in which we prepared mononucleosomes and performed PCR using primer pairs that were internal to the putative nucleosomes. It is possible to assess whether an amplified region is encompassed by a nucleosome by comparing the intensity of PCR products using genomic versus MNase-digested chromatin. Nucleosome-protected regions are resistant to MNase cleavage, whereas nucleosome-free regions are not and will therefore be under-represented relative to undigested genomic DNA (Fig. 7B). These results were again consistent with our nucleosome-mapping data, showing protection by three nucleosomes that flank the E2F sites (Fig. 7B,C). The E2F sites, which are located near the upstream
A

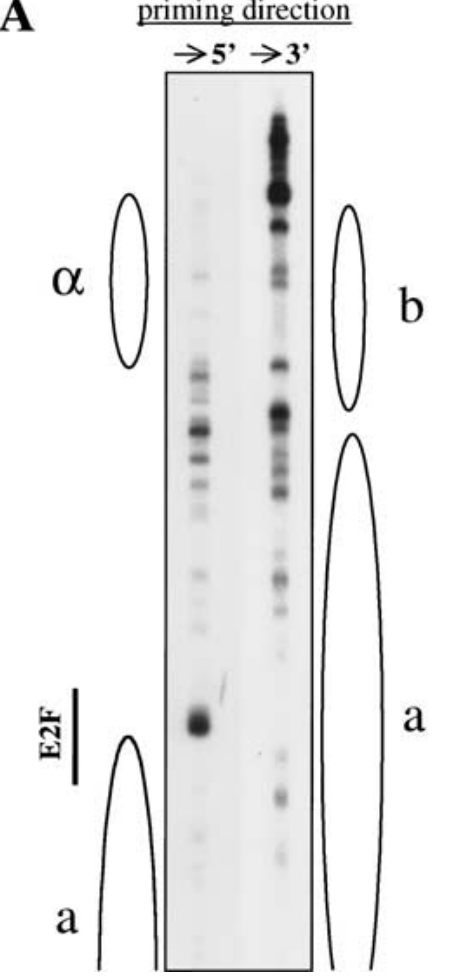

B
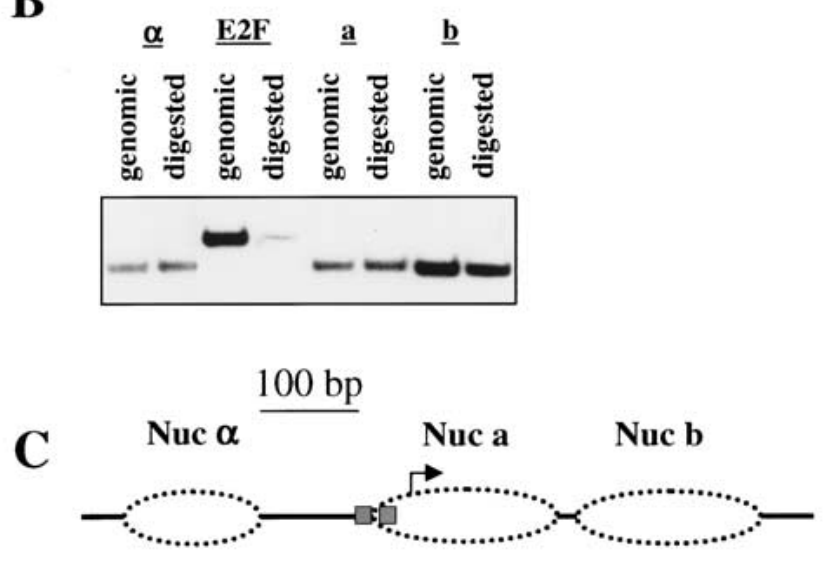

D

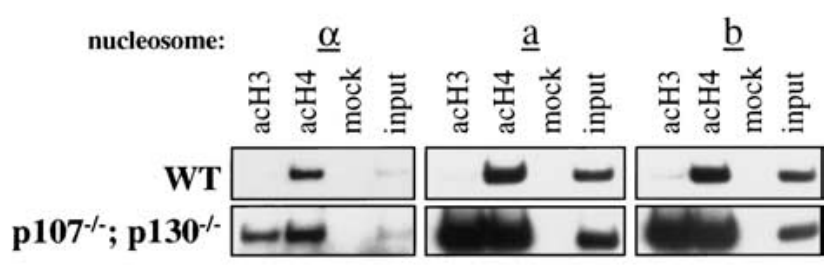

Figure 7. Nucleosome mapping and histone acetylation of the E2F1 promoter. $(A)$ Three promoter-proximal nucleosomes were identified by nucleosome mapping. Chromatin from quiescent wild-type 3T3 cells was partially digested with micrococcal nuclease, and primer extension was performed by use of a set of primer pairs spanning the E2F1 promoter region. Extension products were subjected to ligation-mediated PCR (LM-PCR), followed by acrylamide gel electrophoresis (see Materials and Methods). Amplification products were visualized by autoradiography, and approximate nucleosome boundaries were deduced. (B) Nucleosome positions were confirmed by PCR of genomic vs. MNase-digested chromatin using primer pairs that are internal to the putative nucleosomes or flank the E2F binding sites. Reduction in band intensity in the MNase-treated lanes indicates lack of nucleosome protection. $(C)$ Schematic of nucleosome positioning on the E2F1 promoter. Boxes represent E2F-binding sites, and the arrow corresponds to the major transcription start site. Ovals are enclosed with dotted lines to indicate that nucleosomal positioning is approximate and may be dynamic. (D) Acetylation of nucleosomes at the E2F1 promoter. Chromatin from quiescent primary MEFs was digested extensively with micrococcal nuclease (MNase) to produce mononucleosomes. Chromatin immunoprecipitations were then performed using antibodies against acetylated histones $\mathrm{H} 3$ and $\mathrm{H} 4$, and enrichment was detected by PCR using nucleosome-specific primers (indicated for each of three promoter-proximal nucleosomes) deduced from mapping data in $A$ and $B$. 
boundary of Nuc-a, are susceptible to MNase cleavage, suggesting that the partial overlap with Nuc-a is not sufficient to afford the same degree of protection against MNase cleavage when compared with sequences that are more internal to the nucleosome.

Having identified the positions of nucleosomes within the E2F1 promoter, we then determined the relative levels of histone $\mathrm{H} 3$ and $\mathrm{H} 4$ acetylation in quiescent wildtype MEFs by performing ChIPs on single nucleosomes identified in our nucleosome-mapping studies. Interestingly, we detected significant levels of acetylated histone $\mathrm{H} 4$ associated with each of the three nucleosomes in wild-type cells, whereas minimal amounts of histone H3 acetylation could be detected (Fig. 7D). Next, we analyzed mononucleosomes isolated from $\mathrm{p} 107^{-/-} ; \mathrm{p} 130^{-/-}$ MEFs. Loss of these pocket proteins resulted in a modest increase ( 2-3-fold) in histone $\mathrm{H} 4$ acetylation and a dramatic enhancement ( 20-30-fold) in histone H3 acetylation. These data indicate that HAT activity was recruited to the E2F1 promoter in the mutant MEFs during quiescence, a period in which this promoter is normally inactive. These experiments suggest that (1) in wild-type cells, nucleosomes proximal to the E2F-binding sites in the E2F1 promoter are associated with nonacetylated or underacetylated histone $\mathrm{H} 3$ and acetylated histone $\mathrm{H} 4$; (2) loss of p107 and p130 prevents E2F4 and HDAC recruitment, resulting in modest increases in histone $\mathrm{H} 4$ acetylation and very robust increases in histone $\mathrm{H} 3$ acetylation; and (3) increased nucleosome acetylation in p107 ${ }^{-/-}$; $p 130^{-/-}$MEFs could explain the transcriptional derepression of the E2F1 promoter observed in these quiescent cells (Fig. 4C). One intriguing hypothesis that could account for these observations is that a HAT enzyme is already associated with the E2F1 promoter in normal, quiescent cells, poised for a subsequent activation step later in $G_{1}$ phase. In this setting, HAT activity would only be revealed through the loss of an opposing HDAC, which occurs in $p 107^{-1-}$; $p 130^{-/-}$MEFs (Fig. 4A). An alternative explanation is that exclusion of p107 and p130 from this promoter results in the inappropriate recruitment of HAT activity. In other words, p107/p130 might normally function as a repressor by occluding HAT association with the promoter. Although it is not yet possible to distinguish between these models, which are not mutually exclusive, it is nevertheless clear from these data that loss of HDAC recruitment is correlated with enhanced histone acetylation and activation of the E2F1 promoter.

\section{Discussion}

Gene activation involves the concerted interplay of the general transcription machinery with sequence-specific and chromatin-modifying factors. Covalent modification of nucleosomes represents one mechanism through which chromatin adopts a specific transcriptional state. HDACs are thought to facilitate transcriptional repression by modification of nucleosomal histones, an event antagonized by HATs. Although it is known that chro- matin structure profoundly influences the accessibility of transcription factors to regulatory sequences, the exact mechanisms linking chromatin structure with gene expression in vivo are still unclear. Equally important is the issue of transcriptional specificity, that is, how chromatin-modifying factors are targeted to regulatory sequences by interacting with site-specific DNA-binding proteins. Whereas E2F-mediated repression has proven to be an attractive system in which to study the relationship between E2F/pRB complexes, chromatin-modifying activity, and gene expression, it is unclear how E2F and $\mathrm{pRB}$ regulate transcription in a physiological setting. The problem has been exacerbated by the relative lack of methods that adequately address transcriptional regulation in mammalian cells under physiological conditions and is compounded by the fact that E2F and pRB families are each comprised of multiple members with overlapping specificities. Hence, experiments in which these regulators are ectopically expressed and assayed from transient reporter templates (that are not generally assembled into physiological chromatin) are potentially complicated by loss of specificity and must be interpreted accordingly.

To circumvent these possible complications, we have used a ChIP approach to study the direct binding of factors to promoters in living cells during the cell cycle. In addition, the availability of primary MEFs deficient for one or more $\mathrm{pRB}$ family members allowed us to test the requirement for each of these proteins in factor recruitment. Our studies provide direct and comprehensive evidence that distinct E2F and pRB family members control gene expression in vivo by recruiting specific chromatinmodifying factors and thereby reveal a mechanistic basis for the control of gene expression during the mammalian cell cycle.

\section{Recruitment of corepressors to E2F-responsive promoters}

Previous studies have suggested that E2F might modulate transcription by recruiting a host of chromatinmodifying factors via associated $\mathrm{pRB}$ family members (for review, see Harbour and Dean 2000). The ChIP experiments described here reveal that HDACl and $\mathrm{mSin} 3 \mathrm{~B}$ can be detected on each of the E2F-responsive promoters we examined. Furthermore, corepressor recruitment is cell cycle-dependent, exhibiting significant binding during quiescence and disappearing from promoters by $\mathrm{S}$ phase, when transcriptional activity is maximal. In addition to establishing the identity of the corepressor complex bound in $\mathrm{G}_{0}$, our use of cell lines deficient for pRB family members allowed us to show definitively that $\mathrm{p} 107 / \mathrm{p} 130$, but not $\mathrm{pRB}$, was required to recruit $\mathrm{HDACl}$ specifically. We note that in previous reports, pRB family members were able to bind directly to HDACs in vitro, whereas in others, an adapter protein, RBP1, appeared to serve as a necessary bridging factor (Lai et al. 1999). However, we have thus far been unable to detect RBP1 at promoters in this study using 
several different anti-RBP1 antibodies in ChIP experiments (data not shown). Interestingly, coimmunoprecipitation of p130 and RBP1 could not be shown in the latter study, raising the possibility that the function of RBP1 may be more important for processes that are mediated by $\mathrm{pRb}$ itself.

Despite the absolute dependence of HDAC recruitment on these pocket proteins, p107/p130 were not required to recruit $\mathrm{mSin} 3 \mathrm{~B}$ efficiently to all promoters (including cyclin $A, E 2 F 1$, and $c d c 2$ ), suggesting that an $\mathrm{mSin} 3 \mathrm{~B}$ complex lacking HDAC is able to associate with certain promoters in an E2F- and p107/p130-independent manner. Although it is conceivable that $\mathrm{pRB}$ could compensate for the lack of p107 and p130 and thereby enable $\mathrm{mSin} 3 \mathrm{~B}$ to associate with certain promoters in the absence of p107/p130, we believe this is unlikely, as we have not detected $\mathrm{pRB}$ at these promoters in ChIP experiments. It is more likely that other DNA-binding proteins are able to recruit $\mathrm{mSin} 3 \mathrm{~B}$ in the absence of $\mathrm{E} 2 \mathrm{~F}$, and additional experiments will be required to identify these factors. These data also imply the possibility of a repressor complex that could contain E2F4, p130, and HDAC1, but not mSin3. It will ultimately be of significant interest to determine the functional distinctions between these putative E2F-dependent and E2F-independent corepressor complexes.

For other promoters, such as $B-m y b$, we propose a model in which a functional repressor complex composed of $\mathrm{mSin} 3 \mathrm{~B}, \mathrm{HDAC1}, \mathrm{E} 2 \mathrm{~F} 4$, and $\mathrm{p} 130$ is recruited to promoter DNA in a cell cycle-specific manner (Figs. 2B and $4 \mathrm{~A})$. We have provided the following evidence to support a physiological role for this repressor in regulating $B-m y b$ and other mouse promoters as follows: (1) p130 and E2F4 associate with promoters in primary MEFs exclusively during $G_{0}$ and early $G_{1}$ and depart as cells approach the $\mathrm{G}_{1}$ to $\mathrm{S}$-phase transition; (2) binding of $\mathrm{mSin} 3 \mathrm{~B}$ and HDAC1 (and HDAC2, but not other HDACs that we have tested; data not shown) coincides precisely with the temporal pattern observed for p130 and E2F4; (3) loss of p107 and p130 from quiescent cells results in the concomitant disappearance of E2F4 and HDAC1 from all promoters and the departure of E2F4, $\mathrm{HDAC} 1$, and $\mathrm{mSin} 3 \mathrm{~B}$ from $B-m y b$; (4) the dependency of corepressor recruitment on E2F4/p130 was confirmed by ChIP with cell lines carrying an integrated $B$-myb reporter lacking a functional E2F site. In this setting, E2F binding was essential for recruitment of p130, HDAC1, and $\mathrm{mSin} 3 \mathrm{~B}_{;}(5)$ there was an excellent temporal correlation between recruitment of the repressor, histone deacetylation, and transcriptional repression in wildtype, quiescent MEFs. Subsequent loss of the E2F/corepressor complex in late $G_{1}$ occurred coincident with enhanced histone acetylation and gene activation; and (6) the effects of repressor dissociation during late $G_{1}$ were mimicked by p107/p130 deficiency, which resulted in the acetylation of histones $\mathrm{H} 3$ and $\mathrm{H} 4$ at E2F1 promoter nucleosomes. Taken together, these studies provide compelling evidence for a functional interaction between specific E2F/pRB family members and chromatinmodifying factors in a physiological setting.
Involvement of chromatin remodeling complexes

The use of primary cells deficient for one or more $p R B$ family members revealed other novel mechanistic insights that suggested the involvement of chromatinmodifying enzymes. We found that the loss of p107 and p130 from quiescent cells resulted in enhanced acetylation (relative to wild-type controls) of histones at nucleosomes proximal to E2F-binding sites in the E2F1 promoter. This elevated acetylation of both histones $\mathrm{H} 3$ and $\mathrm{H} 4$ is consistent with the notion that these pocket proteins were responsible for HDAC recruitment. In contrast, loss of $\mathrm{pRB}$ did not result in changes in histone acetylation, in keeping with our observation that HDAC recruitment was not compromised in $R B^{-/-}$MEFs (Fig. $4 \mathrm{~A}$; data not shown). Because the E2F1 promoter is not normally active in quiescent cells, this finding suggests the interesting possibility that a HAT activity is already present at the promoter, even under conditions in which the gene is not active. However, the acetyltransferase activity is kept in check by an HDAC complex also bound to the promoter. Furthermore, although the increase in histone $\mathrm{H} 4$ acetylation in $\mathrm{p} 107^{-/-} ; \mathrm{p} 130^{-/-}$ MEFs was modest, histone $\mathrm{H} 3$ acetylation was dramatically altered, suggesting that a histone $\mathrm{H} 3$-specific HAT, such as GCN5, may have been recruited to the E2F1 promoter. Recruitment of a HAT in $\mathrm{G}_{0}$ or early $\mathrm{G}_{1}$ cells would allow for the rapid activation of a promoter once the E2F4/p130/HDAC complex has dissociated from the promoter as cells progress through $\mathrm{G}_{1}$. Alternatively, our experiments might suggest that p107 and p130 could repress transcription not only by recruiting HDACs, but also by physically excluding a HAT. Such a putative HAT would be recruited in the absence of these pocket proteins but not pRB. Further experiments will be needed to explore these two possibilities and to determine which HATs, if any, are recruited to this promoter, although thus far we have not succeeded in detecting GCN5, P/CAF, or p300/CBP (data not shown).

We have shown that $\mathrm{mSin} 3 \mathrm{~B}$ recruitment occurs in quiescent cells. It is therefore possible that chromatin remodeling factors are recruited with this corepressor because biochemical studies have shown that $\mathrm{mSin} 3$ copurifies with SWI/SNF proteins (Sif et al. 2001). In this latter study, an mSin3 complex was identified that contains hBrm-a SWI/SNF ATPase subunit in addition to HDAC1 and HDAC2. Also, transient transfection experiments have indicated that the pRB family of proteins is able to associate with SWI/SNF (for review, see Harbour and Dean 2000). These data imply that chromatin remodeling and histone acetylation cooperate in transcriptional regulation. Nevertheless, future experiments must address whether acetylation of nucleosomal histones is sufficient for activation of E2F-regulated genes, or whether chromatin remodeling also contributes to the activation of these genes. In this regard, our observation that a nucleosome overlaps the start site of the E2F1 promoter is very interesting because it suggests a mechanism by which the promoter is repressed during quiescence. Furthermore, these nucleosomal histones are dra- 
matically acetylated when the gene is derepressed as a consequence of p107/p130 deficiency, indicating that remodeling of the nucleosome occluding the start site might be coupled to acetylation.

\section{The role of $p R B$}

Another important implication of our work is that p107 and $\mathrm{p} 130$, rather than $\mathrm{pRB}$, appear to selectively recruit HDACs in primary cells. This finding is consistent with the observation that $\mathrm{p} 130$ was the predominant pocket protein recruited to promoters in quiescent human cells (Takahashi et al. 2000). However, our experiments do not rule out the possibility that $\mathrm{pRB}$, and perhaps HDAC, is recruited to promoters under different conditions. For example, in a recent study, pRB was detected on the mouse cyclin $E$ and cyclin $A$ promoters after, but not before, enforced expression of the cyclin/cdk inhibitor, p16 (Dahiya et al. 2001). In addition, pRB was also detected during osteogenic differentiation (Thomas et al. 2001). We therefore favor the hypothesis that $\mathrm{pRB}$ may be recruited specifically to repress promoters (including the ones in our study) under some, but not all, cell cycle withdrawal conditions. Thus, $\mathrm{pRB}$ may play a role in regulating transcription in cells undergoing senescence or differentiation, although it does not a have role in repressing genes during quiescence or early $G_{1}$ phase. Interestingly, $p 107^{-/-} ; p 130^{-/-}$MEFs retain certain growth arrest controls, including intact responses to serum deprivation, contact inhibition, and DNA damage (J-H. Dannenberg and H. te Riele, unpubl.; Harrington et al. 1998), although multiple E2F-responsive genes are derepressed. We speculate that $\mathrm{pRB}$ may regulate other targets that are critical, rate-limiting regulators of the cell cycle.

\section{Model for transcriptional regulation by E2F}

On the basis of these observations, it is now possible to provide a comprehensive model for the physiological regulation of several E2F-responsive genes during the $G_{0}$ to S-phase transition that takes into account endogenous protein localization and promoter recruitment (Fig. 8). Unlike E2F1, E2F2, and E2F3, which are constitutively nuclear, E2F4 lacks a nuclear localization signal. Previ-
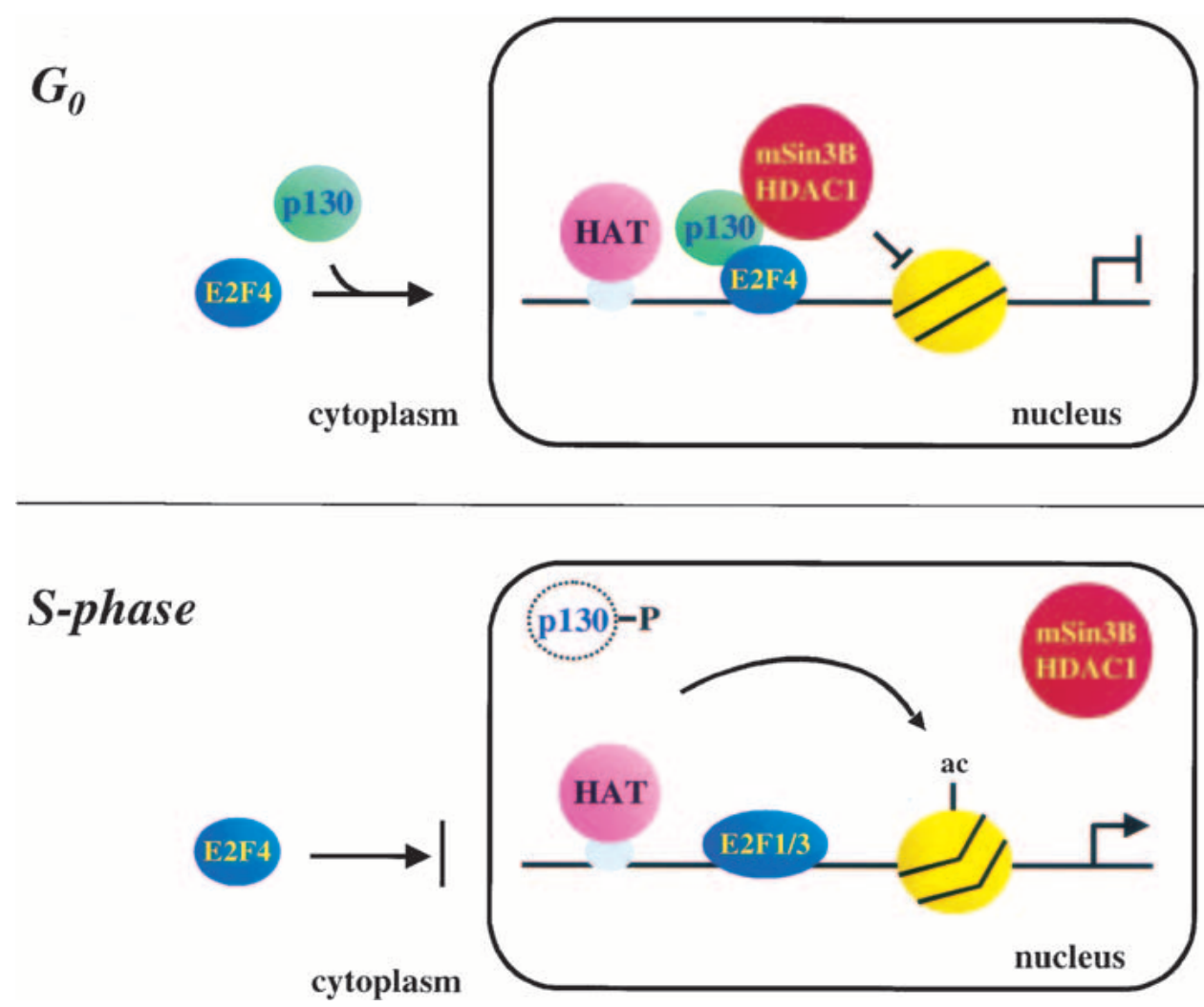

Figure 8. Model describing transcriptional regulation by E2F and pRB families of proteins in vivo. In quiescent MEFs, E2F4 is escorted into the nucleus by 130 . E2F4/p130 then binds to target promoters and recruits a corepressor complex containing mSin $3 \mathrm{~B}$ and HDAC1, although mSin3B may also be recruited by E2F-independent mechanisms. The degree of nucleosome acetylation is determined by the opposing properties of the E2F4/p130/mSin3B/HDAC1 corepressor complex and a putative HAT activity that may be present at the promoter and poised to activate transcription. Corepressor activity maintains the balance of nucleosome acetylation in an underacetylated state. Once cells are stimulated to re-enter the cell cycle, pocket proteins are inactivated by cyclin/cdk complexes, leading to the dissociation of the corepressor complexes. E2F4, lacking a nuclear localization domain, is then excluded from the nucleus. HAT activity, which may be recruited by nuclear activator E2Fs (primarily E2F1 and E2F3) or which may already be present at the promoter, stimulates nucleosome acetylation, leading to gene activation. 
ous experiments suggested that entry of E2F4 (and E2F5) into the nucleus is restricted to cells in $G_{0} /$ early $G_{1}$, and ectopic expression studies further suggested that such localization might depend upon post-translational modification, association with pRB family members, or heterodimerization with DP-2 (Magae et al. 1996; Lindeman et al. 1997; Muller et al. 1997; Verona et al. 1997). Using ChIP, we have shown that recruitment of E2F4 to selected promoters depends on its association with p107/ p130, because these proteins enable E2F4 nuclear localization. Once in the nucleus, E2F4 is able to mediate the recruitment of $\mathrm{mSin} 3 \mathrm{~B} / \mathrm{HDAC} 1$ via pocket proteins, although $\mathrm{mSin} 3 \mathrm{~B}$ recruitment may also occur via E2Findependent mechanisms. It is also possible that this repressor complex assembles prior to promoter recruitment. Once associated with the promoter, the corepressor complex overcomes any putative HAT activity resident at the promoter, and/or prevents HAT recruitment. Thus, the balance of nucleosome acetylation is shifted to an underacetylated state. As cells are stimulated to reenter the cell cycle, pocket proteins are phosphorylated by cyclin-dependent kinases (CDKs), releasing them from E2F4 which, lacking a nuclear localization domain, is free to exit the nucleus. Disassembly of the corepressor complex and recruitment of activator E2Fs (E2F1, E2F2, and E2F3) coincides with the appearance of a HAT activity. This HAT activity, which may have been recruited earlier in the cell cycle or may be recruited concomitant with activator E2Fs, promotes nucleosomal acetylation, resulting in gene activation.

\section{Materials and methods}

\section{Cell lines and FACS analysis}

Wild-type, $R B^{-/-}$, and $p 107^{-/-}$; $p 130^{-/-}$primary MEFs were generated as described previously (Dannenberg et al. 2000). All experiments used low-passage number MEFs. Wild-type and ${\mathrm{E} 2 \mathrm{~F}^{-1-}}^{-}$E2F5-/- $3 \mathrm{~T} 3$ cells were provided by J. Nevins (Duke University Medical Center, Durham, NC). Cells were propagated in DMEM containing 10\% FBS and rendered quiescent by serum withdrawal (no FBS) for $3 \mathrm{~d}$. Cells were restimulated to enter the cell cycle by addition of $20 \%$ FBS (final concentration), and stained with propidium iodide prior to analysis on a FACScan using CellQuest and ModFit software (Becton Dickinson).

\section{Preparation and analysis of stable cell lines containing} $B$-myb promoter

Wild-type and E2F-site mutant $B$-myb promoter fragments were generated by PCR amplification of pGL2-(-536) and pGL2(-536)mut (Lam and Watson 1993), respectively, using a 5' primer, AGCTAAGCTTCCAGTCTTTGCTATGTGTGTG and 3' primer, ACGTAAGCTTCGAGCCGCTCCGGGCCCCAGG. The promoter constructs, which span from -533 to -88 with respect to the start of the coding sequence, were cloned into the HindIII site of pAG/EluW, replacing the SV40 promoter (Klehr et al. 1991). The resulting B-myb-luciferase cassette is flanked by scaffold/matrix attachment regions from the human interferon $\beta$ gene to attenuate positional effects. Promoter constructs were transfected into NIH-3T3 cells by calcium phosphate by use of conditions described previously (Klehr et al. 1991). Stable transfectants were selected with G418 $(0.5 \mathrm{mg} / \mathrm{mL})$, and clones carrying approximately five copies of each transgene were picked. Stable cell lines were propagated in DMEM plus 10\% FBS and were arrested in quiescence by serum withdrawal for 36-48 h. Cell cycle re-entry was stimulated by serum addition (20\% FBS final concentration). To quantitate luciferase expression in the $B-m y b$ reporter cell lines, lysates from equivalent cell numbers for each sample were analyzed by conventional luminometry.

\section{ChIPS}

ChIPs were performed essentially as described (Takahashi et al. 2000). For some experiments, we have also used a modification that bypasses the cesium chloride purification step of the original protocol. Both methods produced similar results. In the modified protocol, cells are cross-linked, lysed, and sonicated as before. Cellular debris is then removed from the suspension by centrifugation at $14,000 \mathrm{~g}$ for $10 \mathrm{~min}$. Immunoprecipitations were then set up as indicated previously, using 2-4 $\mu \mathrm{g}$ of antibody per immunoprecipitation. Antibodies against E2F1 (sc-193), E2F2 (sc-633), E2F3 (sc-878x and sc-879x), E2F4 (sc-1082x), p107 (sc-318), p130 (sc-317), HDAC1 (sc-7872), $\mathrm{mSin} 3 \mathrm{~A}$ (sc-767), and $\mathrm{mSin} 3 \mathrm{~B}$ (sc-768) were obtained from Santa Cruz Biotechnology. Anti-HDAC1 antibody was also purchased from Sigma, and $10 \mu \mathrm{L}$ of IgG antiserum was used in each immunoprecipitation. Antibodies against acetylated histone H3 and acetylated histone $\mathrm{H} 4$ were from Upstate Biotechnology. pAb101, a mouse monoclonal antibody that recognizes the SV40 large-T antigen, was used in the mock immunoprecipitations for most experiments. As before, the immunocomplexes were recovered with protein A/G-Sepharose, washed under stringent conditions, treated with proteinase $\mathrm{K}$ and RNase $\mathrm{A}$ at $55^{\circ} \mathrm{C}$ for $3 \mathrm{~h}$, and followed by overnight reversal of cross-links. The resulting DNA was analyzed by PCR using primers that recognize promoter sequences that flank putative E2F-binding sites. The following pairs of primers were used for each promoter indicated as follows: $B$-myb $\left(5^{\prime}\right.$-CTCGTGTCTTGTACG CTTCGCC-3' and 5'-CACGTTCCCAGGAACTGCAGCT-3'); cyclin A $\left(5^{\prime}\right.$-TGTAAGATTCCCGTCGGGCCTTC-3' and $5^{\prime}$ AGGCGGGAGGAGCGTAGAGCC-3'); E2F1 (5'-ATCGGAGC CTCCGTCGTCACA- 3 ' and 5'-AGGCCGCGGCGAGGGCTCG AT-3'); p107 (5'-TTAGAGTCCGAGGTCCATCTTCT-3' and 5'GGGCTCGTCCTCGAACATATCC-3'); cdc2 (5'-ACAGAGCT CAAGAGTCAGTTGGC- ${ }^{\prime}$ and $5^{\prime}$-CGCCAATCCGATTGCAC GTAGA-3'); actin (5'-GCTTCTTTGCAGCTCCTTCGTTG-3' and $5^{\prime}$-TTTGCACATGCCGGAGCCGTTGT-3').

Experiments were performed a minimum of three, but usually six to eight times, and representative data are shown.

\section{Nuclear and cytoplasmic extractions and immunoblotting}

Cells were harvested and subjected to a modified nuclear/cytoplasmic extraction procedure based as essentially described previously (Muller et al. 1997). Briefly, cells were incubated in hypotonic lysis buffer $(10 \mathrm{mM}$ Tris at $\mathrm{pH} 8,10 \mathrm{mM} \mathrm{NaCl}, 3 \mathrm{mM}$ $\mathrm{MgCl}_{2}, 1 \mathrm{mM}$ EGTA, $10 \mathrm{mM} \beta$-glycerophosphate, $10 \mathrm{mM} \mathrm{NaF}$, $0.1 \mathrm{mM}$ AEBSF, $2 \mu \mathrm{g} / \mathrm{mL}$ leupeptin, $2 \mu \mathrm{g} / \mathrm{mL}$ aprotinin) for 10 min, followed by 20 strokes of a Dounce B homogenizer. The lysates were spun down for $5 \mathrm{~min}$ at $500 \mathrm{~g}$, and the supernatant designated the cytosolic fraction. The nuclear pellet was washed three times in wash buffer (hypotonic lysis buffer adjusted to $0.1 \%$ NP- 40 ), and then treated with nuclear lysis buffer (20 mM HEPES at pH 8, 25\% glycerol, $0.42 \mathrm{M} \mathrm{NaCl}, 1.5 \mathrm{mM}$ $\mathrm{MgCl}_{2}, 0.2 \mathrm{mM}$ EDTA, $0.5 \mathrm{mM}$ DTT, $10 \mathrm{mM} \beta$-glycerophosphate, $10 \mathrm{mM} \mathrm{NaF}, 0.1 \mathrm{mM}$ AEBSF, $2 \mu \mathrm{g} / \mathrm{mL}$ leupeptin, $2 \mu \mathrm{g} / \mathrm{mL}$ aprotinin) for $30 \mathrm{~min}$ while rocking at $4^{\circ} \mathrm{C}$. The lysate was spun down at 14,000 $\mathrm{g}$ for $30 \mathrm{~min}$, and the supernatant designated the 
nuclear fraction. Protein concentration was determined by Bradford assay. A total of 20-50 $\mathrm{\mu g}$ of each nuclear and cytoplasmic sample were resolved by SDS-PAGE ( $10 \%$ acrylamide). Western blotting with LLF4-2 antibody (kind gift of J. Lees, Massachusetts Institute of Technology, Cambridge) was used to detect E2F4. To verify the integrity of the nuclear and cytoplasmic fractions, the same blot was sequentially stripped and reprobed with anti-Sp1 (Santa Cruz, sc-59) and anti-Eps15 (Santa Cruz, sc-1840) antibodies, respectively.

\section{RT-PCR analysis}

Total RNA was prepared using Trizol Reagent (GIBCO) according to the manufacturer's protocol. A total of $100 \mathrm{ng}$ of template RNA was amplified by RT-PCR using the SuperScript One-Step RT-PCR kit (Invitrogen). Primer sequences were based on cDNA sequences corresponding to each of the genes analyzed. A total of 17 (actin), 25 (B-myb, cdc2, cyclin $A$, cyclin $E)$, or 35 (E2F1) cycles of PCR were used. PCR conditions were determined previously to be in the linear range of amplification. RT-PCR products were resolved by agarose gel electrophoresis and visualized by ethidium bromide staining.

Nucleosome mapping of the E2F1 promoter and mononucleosome ChIPs

Cells were cross-linked with formaldehyde, harvested, and lysed as in the ChIP protocol described above, except that in lieu of the third lysis/sonication step, cells were resuspended in 2 $\mathrm{mL}$ of MNase buffer (10 mM Tris at pH 7.4, $60 \mathrm{mM} \mathrm{KCl}, 15 \mathrm{mM}$ $\mathrm{NaCl}, 2 \mathrm{mM} \mathrm{CaCl}_{2}, 0.15 \mathrm{mM}$ spermine, $0.5 \mathrm{mM}$ spermidine). A total of $200 \mu \mathrm{L}$ of nuclei suspension was treated with $\sim 100 \mathrm{U}$ MNase at room temperature for $10 \mathrm{~min}$. The reaction was quenched with EDTA (10 mM final concentration). Cross-links were reversed and DNA was extracted according to the ChIP protocol. Before the primer extension step, $1 \mu \mathrm{g}$ of DNA template was treated with polynucleotide kinase at $37^{\circ} \mathrm{C}$ for $1 \mathrm{~h}$, followed by phenol: chloroform extraction and ethanol precipi-

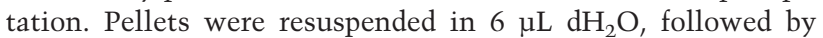
addition of $2 \mu \mathrm{L}$ of $10 \times$ Vent buffer and $3 \mu \mathrm{L}$ of gene-specific primer $(0.2$ pmole $/ \mu \mathrm{L})$. Samples were incubated at $95^{\circ} \mathrm{C} / 10 \mathrm{~min}$ and then $65^{\circ} \mathrm{C} / 30 \mathrm{~min}$. Vent Taq polymerase $(3 \mathrm{U})$ and $7.5 \mu \mathrm{L}$ Mg-dNTP solution (20 $\mathrm{mM} \mathrm{MgSO}_{4}, 20 \mathrm{mM} \mathrm{DTT}, 0.25 \mathrm{M}$ dNTP) were added, followed by incubation at $74^{\circ} \mathrm{C} / 15 \mathrm{~min}$. DNA was phenol:chloroform extracted and ethanol precipitated. Fragments were amplified by ligation-mediated PCR (LM-PCR) using primers that recognize sequences specific to the gene and linker DNA and resolved by $8 \%$ polyacrylamide-urea gel. Approximate nucleosome boundaries were calculated on the basis of an adjacent sequencing ladder. To confirm nucleosome positions, PCR was performed on genomic and MNase-treated chromatin using primer pairs that are internal to the putative nucleosomes. MNase-treated chromatin was determined to be $>90 \%$ mononucleosomal on the basis of agarose gel electrophoresis. Cross-linked chromatin was reversed and extracted as described for our ChIPs protocol following MNase digestion. Equal amounts (by $\mathrm{OD}_{260}$ ) of genomic versus MNase-treated chromatin were used as template for PCR. Mononucleosomes prepared in this manner were also subjected to ChIP analysis using the following primers: nucleosome $\alpha\left(5^{\prime}\right.$-GTGAAGGG GCGGGGCCCATT-3' and 5'-CGGTGCCGGGCGCCTTCTC CCCT-3'); nucleosome a (5'-CCCTCGCCGCGGCCTGCCAG TCAT-3' and 5'-CATGGCGCTCACGGCCCGCGT-3'); nucleosome b (5'-CCGATGTCGGCGCCCCGCAGCT-3' and 5'CGTGGCGAAGAGCAGCACGT-3'). To amplify the E2F sites, PCR was performed with the same primers used in the ChIP experiments.

\section{Acknowledgments}

We thank J. Nevins, R. Rempel, S. Gaubatz, and D. Livingston for 3T3 cells lacking E2F4 and E2F5; J. Lees and J. DeCaprio for antibodies; and J. Lees, B. Kingston, T. Maniatis, P. Nakatani, I. Sanchez, H. Cam, and E. Balciunaite for helpful comments throughout the course of this work. J.B.R. is supported by a Howard Hughes Medical Institute Pre-doctoral Fellowship. B.D.D. gratefully acknowledges the support of the NCI (CA77245-02) and the Pew Scholars Program in the Biomedical Sciences.

The publication costs of this article were defrayed in part by payment of page charges. This article must therefore be hereby marked "advertisement" in accordance with 18 USC section 1734 solely to indicate this fact.

\section{References}

Alland, L., Muhle, R., Hou, Jr., H., Potes, J., Chin, L., SchreiberAgus, N., and DePinho, R.A. 1997. Role for N-CoR and histone deacetylase in Sin3-mediated transcriptional repression. Nature 387: 49-55.

Ayer, D.E., Lawrence, Q.A., and Eisenmann, R.N. 1995. MadMax transcriptional repression is mediated by ternary complex formation with mammalian homologs of yeast repressor Sin3. Cell 80: 767-776.

Brehm, A., Miska, E.A., McCance, D.J., Reid, J.L., Bannister, A.J., and Kouzarides, T. 1998. Retinoblastoma protein recruits histone deacetylase to repress transcription. Nature 391: 597-601.

Cobrinik, D., Lee, M.-H., Hannon, G., Mulligan, G., Bronson, R.T., Dyson, N., Harlow, E., Beach, D., Weinberg, R.A., and Jacks, T. 1996. Shared role of the pRB-related p130 and p107 proteins in limb development. Genes \& Dev. 10: 1633-1644.

Dahiya, A., Wong, S., Gonzalo, S., Gavin, M., and Dean, D.C. 2001. Linking the $\mathrm{Rb}$ and polycomb pathways. Mol. Cell 8: $557-568$.

Dannenberg, J.H., van Rossum, A., Schuijff, L., and te Riele, H. 2000. Ablation of the retinoblastoma gene family deregulates $G_{1}$ control causing immortalization and increased cell turnover under growth-restricting conditions. Genes \& Dev. 14: 3051-3064.

Dunaief, J.L., Strober, B.E., Guha, S., Khavari, P.A., Alin, K., Luban, J., Begemann, M., Crabtree, G.R., and Goff, S.P. 1994 The retinoblastoma protein and BRG1 form a complex and cooperate to induce cell cycle arrest. Cell 79: 119-130.

Dyson, N. 1998. The regulation of E2F by pRB-family proteins. Genes \& Dev. 12: 2245-2262.

Ferreira, R., Magnaghi-Jaulin, L., Robin, P., Harel-Bellan, A., and Trouche, D. 1998. The three members of the pocket proteins family share the ability to repress E2F activity through recruitment of a histone deacetylase. Proc. Natl. Acad. Sci. 95: $10493-10498$.

Ferreira, R., Naguibneva, I., Mathieu, M., Ait-Si-Ali, S., Robin, P., Pritchard, L.L., and Harel-Bellan, A. 2001. Cell cycle-dependent recruitment of HDAC-1 correlates with deacetylation of histone $\mathrm{H} 4$ on an Rb-E2F target promoter. EMBO Rep. 2: 794-799.

Gaubatz, S., Lees, J.A., Linderman, G.J., and Livingston, D.M. 2001. E2F4 is exported from the nucleus in a CRM1-dependent manner. Mol. Cell. Biol. 21: 1384-1392.

Harbour, J.W. and Dean, D.C. 2000. Chromatin remodeling and Rb activity. Curr. Opin. Cell. Biol. 12: 685-689.

Harrington, E.A., Bruce, J.L., Harlow, E., and Dyson, N. 1998. pRB plays an essential role in cell cycle arrest induced by DNA damage. Proc. Nat1. Acad. Sci. 95: 11945-11950. 
Hassig, C.A., Fleischer, T.C., Billin, A.N., Schreiber, S.L., and Ayer, D.E. 1997. Histone deacetylase activity is required for full transcriptional repression by mSin3A. Cell 89: 341-347.

Hsiao, K.-M., McMahon, S.L., and Farnham, P.J. 1994. Multiple DNA elements are required for the growth regulation of the mouse E2F1 promoter. Genes \& Dev. 8: 1526-1537.

Humbert, P.O., Verona, R., Trimarchi, J.M., Rogers, C., Dandapani, S., and Lees, J.A. 2000. E2f3 is critical for normal cellular proliferation. Genes \& Dev. 14: 690-703.

Hurford, Jr., R.K., Cobrinik, D., Lee, M.-H., and Dyson, N. 1997. $\mathrm{pRB}$ and $\mathrm{p} 107 / \mathrm{p} 130$ are required for the regulated expression of different sets of E2F responsive genes. Genes \& Dev. 11: $1447-1463$

Kadosh, D. and Struhl, K. 1997. Repression by Ume6 involves recruitment of a complex containing Sin3 corepressor and Rpd3 histone deacetylase to target promoters. Cell 89: 365371.

Khochbin, S., Verdel, A., Lemercier, C., and Seigneurin-Berny, D. 2001. Functional significance of histone deacetylase diversity. Curr. Opin. Gen. Dev. 11: 162-166.

Klehr, D., Maass, K., and Bode, J. 1991. Scaffold-attached regions from the human interferon $\beta$ domain can be used to enhance the stable expression of genes under the control of various promoters. Biochemistry 30: 1264-1270.

Knoepfler, P.S. and Eisenmann, R.N. 1999. Sin meets NuRD and other tails of repression. Cell 99: 447-450.

Laherty, C.D., Yang, W.M., Sun, J.M., Davie, J.R., Seto, E., and. Eisenman, R.N. 1997. Histone deacetylases associated with the $\mathrm{mSin} 3$ corepressor mediate mad transcriptional repression. Cell 89: 349-356.

Lai, A., Lee, J.M., Yang, W.M., DeCaprio, J.A., Kaelin, W.G.J., Seto, E., and Branton, P.E. 1999. RBP1 Recruits both histone deacetylase-dependent and -independent repression activities to retinoblastoma family proteins. Mol. Cell. Biol. 19: 6632-6641

Lai, A., Kennedy, B.K., Barbie, D.A., Bertos, N.R., Yang, X.J., Theberge, M., Tsai, S., Seto, E., Zhang, Y., Kuzmichev, A., et al. 2001. RBP1 recruits the mSIN3-histone deacetylase complex to the pocket of retinoblastoma tumor supressor family proteins found in limited discrete regions of the nucleus at growth arrest. Mol. Cell. Biol. 21: 2918-2932.

Lam, E.W.-F. and Watson, R.J. 1993. An E2F-binding site mediates cell-cycle regulated repression of mouse $B-m y b$ transcription. EMBO T. 12: 2705-2713.

Leone, G., DeGregori, J., Yan, Z., Jakoi, L., Ishida, S., Williams, R.S., and Nevins, J.R. 1998. E2F3 activity is regulated during the cell cycle and is required for the induction of $\mathrm{S}$ phase. Genes \& Dev. 12: 2120-2130.

Lindeman, G.J., Gaubatz, S., Livingston, D.M., and Ginsberg, D. 1997. The subcellular localization of E2F-4 is cell-cycle dependent. Proc. Nat1. Acad. Sci. 94: 5095-5100.

Luo, R.X., Postigo, A.A., and Dean, D.C. 1998. Rb interacts with histone deacetylase to repress transcription. Cell 92: 463473.

Magae, J., Wu, C.L., Illenye, S., Harlow, E., and Heintz, N.H. 1996. Nuclear localization of DP and E2F transcription factors by heterodimeric partners and retinoblastoma protein family members. J. Cell Sci. 109: 1717-1726.

Magnaghi-Jaulin, L., Groisman, R., Naguibneva, I., Robin, P., Lorain, S., Le Villain, J.P., Troalen, F., Trouche, D., and Harel-Bellan, A. 1998. Retinoblastoma protein represses transcription by recruiting a histone deacetylase. Nature 391: 601-605.

Muller, H., Moroni, M.C., Vigo, E., Petersen, B.O., Bartek, J., and Helin, K. 1997. Induction of S-phase entry by E2F transcription factors depends on their nuclear localization. Mol. Cell.
Biol. 17: 5508-5520.

Nagy, L., Kao, H.Y., Chakravarti, D., Lin, R.J., Hassig, C.A., Ayer, D.E., Schreiber, S.L., and Evans, R.M. 1997. Nuclear receptor repression mediated by a complex containing SMRT, mSin3A, and histone deacetylase. Cell 89: 373-380.

Parekh, B.S. and Maniatis, T. 1999. Virus infection leads to localized hyperacetylation of histones $\mathrm{H} 3$ and $\mathrm{H} 4$ at the IFN- $\beta$ promoter. Mol. Cell 3: 125-129.

Ren, B., Cam, H., Takahashi, Y., Volkert, T., Terragni, J., Young, R., and Dynlacht, B. 2002. E2F integrates cell cycle progression with DNA repair, replication, and $\mathrm{G}_{2} / \mathrm{M}$ checkpoints. Genes \& Dev. 16: 245-256.

Ross, J.F., Liu, X., and Dynlacht, B.D. 1999. Mechanism of transcriptional repression of E2F by the retinoblastoma tumor suppressor protein. Mol. Cell 3: 195-205.

Ross, J.F., Naar, A., Cam, H., Gregory, R., and Dynlacht, B.D. 2001. Active repression and E2F inhibition by pRB are biochemically distinguishable. Genes \& Dev. 15: 392-397.

Schreiber-Agus, N., Chin, L., Chen, K., Torres, R., Rao, G., Guida, P., Skoultchi, A.I., and DePinho, R.A. 1995. An amino-terminal domain of Mxil mediates anti-myc oncogenic activity and interacts with a homolog of the yeast transcriptional repressor SIN3. Cell 80: 777-786.

Sif, S., Saurin, A.J., Imbalzano, A.N., and Kingston, R.E. 2001. Purification and characterization of mSin3A-containing Brg1 and hBrm chromatin remodeling complexes. Genes \& Dev. 15: 603-618.

Strober, B.E., Dunaief, J.L., Guha, S., and Goff, S.P. 1996. Functional interactions between the hBRM/hBRG1 transcriptional activators and the pRB family of proteins. Mol. Cell. Biol. 16: 1576-1583.

Takahashi, Y., Rayman, J.B., and Dynlacht, B.D. 2000. Analysis of promoter binding by the E2F and pRB families in vivo: Distinct E2F proteins mediate activation and repression. Genes \& Dev. 14: 804-816.

Thomas, D.M., Carty, S.A., Piscopo, D.M., Lee, J.S., Wang, W.F., Forrester, W.C., and Hinds, P.W. 2001. The retinoblastoma protein acts as a transcriptional coactivator required for osteogenic differentiation. Mol. Cell 8: 303-316.

Trouche, D., Cook, A., and Kouzarides, T. 1996. The CBP coactivator stimulates E2F1/DP1 activity. Nucleic Acids Res. 24: 4139-4145.

Verona, R., Moberg, K., Estes, S., Starz, M., Vernon, J.P., and Lees, J.A. 1997. E2F activity is regulated by cell cycle-dependent changes in subcellular localization. Mol. Cell. Biol. 17: 7268-7282.

Washburn, B.K. and Esposito, R.E. 2001. Identification of the Sin3-binding site in Ume6 defines a two-step process for conversion of Ume6 from a transcriptional repressor to an activator in yeast. Mol. Cell. Biol. 21: 2057-2069.

Wells, J., Boyd, K.E., Fry, C.J., Bartley, S.M., and Farnham, P.J. 2000. Target gene specificity of E2F and pocket protein family members in living cells. Mol. Cell. Biol. 20: 5797-5807.

Wu, L., Timmers, C., Maiti, B., Saavedra, H., Sang, L., Chong, G., Nuckolls, F., Giangrande, P., Wright, F., Field, S., et al. 2001. The E2F1-3 transcription factors are essential for cellular proliferation. Nature 414: 457-462.

Zhang, H.S., Gavin, M., Dahiya, A., Postigo, A.A., Ma, D., Luo, R.X., Harbour, J.W., and Dean, D.C. 2000. Exit from G1 and $\mathrm{S}$ phase of the cell cycle is regulated by repressor complexes containing HDAC-Rb-hSWI/SNF and Rb-hSWI/SNF. Cell 101: 79-89.

Zhang, Y., Iratni, R., Erdjument-Bromage, H., Tempst, P., and Reinberg, D. 1997. Histone deacetylases and SAP18, a novel polypeptide, are components of a human Sin 3 complex. Cell 89: $357-364$. 


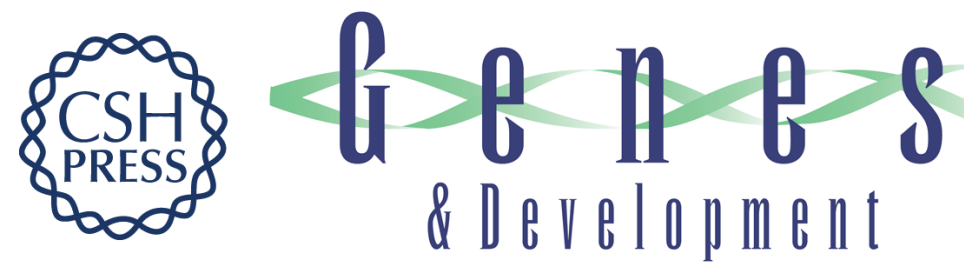

\title{
E2F mediates cell cycle-dependent transcriptional repression in vivo by recruitment of an HDAC1/mSin3B corepressor complex
}

\author{
Joseph B. Rayman, Yasuhiko Takahashi, Vahan B. Indjeian, et al.
}

Genes Dev. 2002, 16:

Access the most recent version at doi:10.1101/gad.969202

\section{References This article cites 48 articles, 23 of which can be accessed free at: http://genesdev.cshlp.org/content/16/8/933.full.html\#ref-list-1 \\ License}
Email Alerting Receive free email alerts when new articles cite this article - sign up in the box at the top right corner Service of the article or click here.

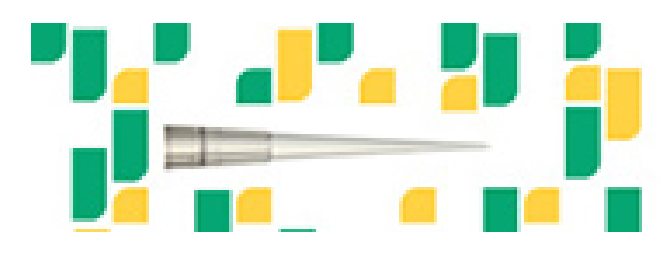

